Journal of Nuclear Medicine, published on March 12, 2021 as doi:10.2967/jnumed.120.256776

\title{
Exploiting the MUC5AC Antigen for Noninvasive Identification of Pancreatic Cancer
}

Running Title: MUC5AC-Targeted Immuno-PET in Pancreatic Cancer

Authors and Affiliations: Kelly E. Henry ${ }^{1 \dagger}$, Travis M. Shaffer ${ }^{1,2 \dagger}$, Kyeara N. Mack ${ }^{1,3}$, Janine Ring $^{1}$, Anuja Ogirala ${ }^{1}$, Susanne Klein-Scory ${ }^{4}$, Christina Eilert-Micus ${ }^{4}$, Wolff Schmiegel ${ }^{4}$, Thilo Bracht $^{5}$, Barbara Sitek ${ }^{5}$, Marguerite Clyne ${ }^{6}$, Colm J. Reid ${ }^{6}$, Bence Sipos ${ }^{7}$, Jason S. Lewis ${ }^{1,3,8,9}$, Holger Kalthoff ${ }^{10}$, Jan Grimm ${ }^{1,3,8 *}$

${ }^{1}$ Department of Radiology, Memorial Sloan Kettering Cancer Center, New York, NY ${ }^{2}$ Department of Radiology, Stanford University, Stanford, CA

${ }^{3}$ Molecular Pharmacology Program, Memorial Sloan Kettering Cancer Center, New York, NY ${ }^{4}$ Department of Medicine, Ruhr University Bochum, Bochum, Germany

${ }^{5}$ Medical Proteome Center, Ruhr University Bochum, Bochum, Germany

${ }^{6}$ School of Medicine University College Dublin, Health Sciences Centre, Dublin, Ireland

${ }^{7}$ Department of Medical Oncology and Pneumology, University Hospital Tübingen, Tübingen, Germany

${ }^{8}$ Departments of Pharmacology and Radiology, Weill Cornell Medical College, New York, NY ${ }^{9}$ Radiochemistry and Molecular Imaging Probes Core, Memorial Sloan Kettering Cancer Center, New York, NY

${ }^{10}$ Institute for Experimental Cancer Research, Christian-Albrechts University, Kiel, Germany

*J.G. - grimmj@mskcc.org, P: 646-888-3095 F: 646-888-3059, *Corresponding Author

†K.E.H. - Kelly.henry89@gmail.com, P: 315-569-7733, Postdoctoral Research Fellow

†T.M.S. - trvsshaffer@gmail.com, P: 724-679-5548, Postdoctoral Research Fellow

tDenotes equal contribution

Financial Support: See Acknowledgements Section.

Word Count: 4978 


\section{ABSTRACT:}

Pancreatic cancer $(P C)$ remains the $4^{\text {th }}$ leading cause of cancer death; therefore, there is a clinically unmet need for novel therapeutics and diagnostic markers to treat this devastating disease. Physicians often rely on biopsy or CT for diagnosis, but more specific protein biomarkers are highly desired to assess the stage and severity of PC in a noninvasive manner. Serum biomarkers such as CA19.9 are of particular interest as they are commonly elevated in PC but have exhibited suboptimal performance in the clinic. MUC5AC has emerged as a useful serum biomarker that is specific for PC vs. inflammation. We developed RA96, an anti-MUC5AC antibody, to gauge its utility in PC diagnosis through immunohistochemical (IHC) analysis and whole-body PET in PC.

Methods: In this study, extensive biochemical characterization determined MUC5AC as the antigen for RA96. We then determined the utility of RA96 for MUC5AC IHC on clinical PC and pre-clinical PC. Finally, we radiolabeled RA96 with zirconium-89 to assess its application as a whole-body PET radiotracer for MUC5AC quantification in PC.

Results: Immunohistochemical staining with RA96 distinguished chronic pancreatitis (CP), PanIN, and varying grades of pancreatic ductal adenocarcinoma (PDAC) in clinical samples. [ ${ }^{89} \mathrm{Zr}$ ]Zr-DFO-RA96 was able to detect MUC5AC with high specificity in mice bearing capan-2 xenografts.

Conclusion: Our study demonstrates that RA96 can differentiate between inflammation and PC, improving the fidelity of PC diagnosis. Our immuno-PET tracer $\left[{ }^{89} \mathrm{Zr}\right] \mathrm{Zr}$-DFO-RA96 shows specific detection of MUC5AC+ tumors in vivo, highlighting the utility of MUC5AC targeting for diagnosis of PC.

KEY WORDS: Pancreatic cancer, RA96, Immuno-PET, Zirconium-89, MUC5AC 


\section{INTRODUCTION}

Pancreatic cancer (PC) is a devastating disease with a five-year survival rate of only $9 \%$ (1). Poor survival for PC patients is most often associated with a late stage diagnosis, when the disease has already spread and continues to exhibit rapid metastatic progression. PC has few reliable biomarkers that are able to properly diagnose and guide treatment, especially within the window of early detection. As PC is inevitably more difficult to treat at this stage, biomarkers that can diagnose $\mathrm{PC}$ in asymptomatic patients may allow more patients to undergo potential curative tumor resection and greatly improve their prognosis.

Serum biomarkers as an indicator for disease are incredibly useful can be tested routinely from blood work in patients (2). Elevated levels of carbohydrate antigen 19.9 (CA19-9) in the blood of patients with PC are typically a red flag in the clinical follow-up (3). If CA19-9 levels are abnormal, recurrence has to be assumed and patients are guided to have additional work-up, including abdominal CT scans or MRI (4). However, CA19-9 is only elevated in $\sim 65 \%$ of PC, is not always elevated early on in disease, and can also be elevated in non-malignant conditions such as chronic pancreatitis (CP) and other inflammatory disorders (2). As such, CA19-9 remains suboptimal for $\mathrm{PC}$ detection.

Recent evidence has shown that other serum biomarkers such as mucins may be more specific and detectable, particularly for differentiating inflammation from oncogenic lesions (5, 6). Comprehensive genomic analyses of normal pancreas vs. CP and PC tissue identified MUC5AC as the most differentially expressed mucin gene compared with benign pancreatic pathologies $(5,7,8)$. MUC5AC belongs to a group of high molecular O-glycoproteins that are either secreted or membrane bound (5). MUC5AC was further validated as a useful biomarker both in tandem with CA19-9 as well as independently when it comes to PC diagnosis (8-10) but has never been targeted for imaging. 
In this study, we develop an antibody against MUC5AC and apply it for both immunohistochemical analysis and immuno-PET for PC diagnosis. Uptake of radiolabeled MUC5AC shows successful tumor delineation in a PC xenograft out to $144 \mathrm{~h}$ post-injection of radiotracer. The uptake of our radiotracer in vivo is blockable, which is demonstrated by a coinjection of excess unlabeled antibody and also has significantly increased uptake compared to the IgG control $(P<0.001)$, marking its specificity for the MUC5AC target. We postulate that our anti-MUC5AC antibody has the potential to improve diagnosis of PC both in vivo and ex vivo and change the paradigm for PC serum biomarkers.

\section{MATERIALS AND METHODS}

Cell culture. All tissue culture was performed using sterile techniques, and all cells were grown at $37{ }^{\circ} \mathrm{C}$ and $5 \% \mathrm{CO}_{2}$ in a humidified atmosphere according to ATCC instructions. All of the cell lines discussed in this article were thawed from the same original stocks and routinely tested for mycoplasma contamination.

RA96 antibody, protein extraction, and RA96 antigen preparation. RA96 antibody was developed against intra and inter-cellular tumor-associated antigens. Secretomes were harvested from $48 \mathrm{~h}$ serum free cultured cell supernatant and prepared as previously described by us (11). Aliquots of lysates $(50 \mu \mathrm{g})$ or aliquots of secretomes $(15 \mu \mathrm{g})$ were separated in the horizontal $<5 \mathrm{~mm}$ thick $1 \%$ agarose gels (HEEO ultra; CarlRoth, Karlsruhe, Germany) with TEA running buffer (40 $\mathrm{mM}$ Tris-acetate, $1 \mathrm{mM}$ EDTA, $0.1 \%$ SDS, $\mathrm{pH} 8.0$, according to previously published procedures (12).

Immunoprecipitation. As antigen sources, the secretomes $(40 \mu \mathrm{g})$ or the lysates $(200 \mu \mathrm{g})$ from RA96 reactive and non-reactive cells were used for immunoprecipitation. For comparative analyses an alternative antibody against MUC5AC, 2-11M1 were used in parallel to the RA96 
hybridoma supernatant. The antibody $2-11 \mathrm{M} 1$ detects the globular D1/D2 domain located in the $\mathrm{N}$-terminus of MUC5AC (13).

Mass spectrometry and data mining. Gel pieces containing the antibody reactive or corresponding non-reactive signals were excised out of the non-blotted gel part corresponding to the RA96 reactive region and subjected to the tryptic digestion procedure. The peptides were analyzed by liquid chromatography- tandem mass spectrometry (LC-MS/MS) on a Q Exactive HF instrument (Thermo Fisher Scientific) coupled to an Ultimate 3000 RSLCnano HPLC System (Dionex, Idstein, Germany) as described previously (14). The lists of identified proteins from positive and corresponding negative samples were compared and accession numbers found exclusively in positive control gel pieces were defined (Supplementary Table 1). A compilation of annotated MS/MS spectra can be found in the Supplementary Materials. Further criteria to the antigen identification were that the putative RA96 antigen must be a high molecular mass protein of more than $300 \mathrm{kDa}$ and could be associated or belong to the mucin family (15).

Knockdown of MUC5AC and recombinant expression of MUC5AC fragments. In order to further demonstrate that MUC5AC is the antigen for RA96 antibody we performed siRNA knockdown experiments and expression experiments of recombinant MUC5AC fragments in negative cell lines. For siRNA experiments, cells were grown to a confluency of approximately $30 \%$ and incubated with $100 \mu \mathrm{M}$ ON-TARGETplus siRNA (ON-TARGETplus MUC5AC siRNA D-001810-02-05, Dharmacon, GE Healthcare) or Dharmacon ON-TARGETplus non-targeting siRNA (Non-Targeting siRNA \#2, Lot 1876332) as a control using Dharmafect (Dharmacon GE healthcare) for two days followed by incubation in serum-free medium for another two days. The protein samples were analyzed by immune blots with RA96. For expression of recombinant MUC5AC, fragments COS7 cells and Paca44 cells were transfected with the MUC5AC sequences bearing pcDNA3.1 expression system as previously described (12). N-terminal coding, C-terminal, N+2TR+Cterminal MUC5AC coding sequences and gfp-pcDNA3.1 control 
DNA were transferred to cells using effectene transfection procedure (Qiagen, Germany). Three days after transfection the proteins were prepared, separated by NUPAGE $7 \%$ gels (Pierce, Thermofisher Scientific), transferred to PVDF-FL membrane and probed by RA96 and antiMuc5AC 2-11M1.

Immunohistochemistry with RA96. The tissue microarray (TMA) was constructed as described previously (16). Briefly, six TMAs containing 300 cores of normal ducts and PanINs, originating from 21 disease-free pancreata and 81 resected pancreata because of different neoplasms, 30 alcoholic chronic pancreatitis and 10 autoimmune pancreatitis specimens and 48 PDACs (G1-G3). Immunohistochemical staining was performed with RA96, including the deparaffinization of the formalin-fixed paraffin-embedded tissue sections and the heat-induced antigen-retrieval. The intensity of the reactions was scored as mild, moderate, or strong (score 1,2 , or 3 , respectively) by an experienced pathologist (B.S.).

Preparation and radiolabeling of [ ${ }^{89} \mathrm{Zr}$ ]Zr-DFO-antibodies. RA96 and isotype-matched IgG ( $150 \mathrm{kDa})$ were functionalized with p-isothiocyanatobenzyl-desferrioxamine (DFO-Bn-NCS; Macrocyclics, Inc.) as described previously (17). DFO-antibody conjugates were analyzed via matrix-assisted light desorption-ionization time-of-flight mass spectrometry and found to have 34 chelates/antibody. Zirconium-89 $\left({ }^{89} \mathrm{Zr}\right)$ was produced through proton beam bombardment of yttrium foil and isolated in high purity as $\left.{ }^{89} \mathrm{Zr}\right] \mathrm{Zr}$-oxalate at Memorial Sloan Kettering Cancer Center (MSK) according to published procedures (18). DFO-RA96 and DFO-IgG were incubated with neutralized $\left[{ }^{89} \mathrm{Zr}\right] \mathrm{Zr}$-oxalate in chelex PBS at $\mathrm{pH} 7.0$ and $37{ }^{\circ} \mathrm{C}$ for $1 \mathrm{~h}$. Radioconjugates were purified using disposable size-exclusion (PD-10) columns with PBS buffer exchange and characterized via instant thin-layer chromatography.

Small animal models. All animal studies were conducted in accordance with the guidelines set by the Institutional Animal Care and Use Committee at MSK. Female athymic nude (NU/NU) mice (Charles River Laboratories, 6-8 weeks, 20-22 g) were implanted subcutaneously with 
Capan-2 cells $\left(5 \times 10^{6} /\right.$ mouse $)$ in the lower right flank in $200 \mu \mathrm{L}$ of $1: 1$ media:Matrigel (BD Biosciences) and grown to a tumor volume of approximately $100-150 \mathrm{~mm}^{3}$ (4-5 weeks) prior to imaging studies. Mia PaCa-2, Capan-2, and Capan-1 cells were implanted orthotopically into the head of the pancreas of female athymic nude mice (40K cells, 1:1 Matrigel, $20 \mu \mathrm{L}$ ). Tumors were palpated weekly and grown to a tumor volume of approximately $150-200 \mathrm{~mm}^{3}$ (4-5 weeks).

ELISA on serum samples. Serum samples were collected from animals 1 week prior to imaging studies. MUC5AC levels were detected with human MUC5AC ELISA kit (Aviva Systems Biology) according to the manufacturer's instructions.

In vivo imaging. Mice were anesthetized with $1.5 \%-2 \%$ isoflurane (Baxter Healthcare) supplemented with medical air. Mice were administered [ $\left.{ }^{89} \mathrm{Zr}\right] \mathrm{Zr}$-DFO-RA96 or [ $\left.{ }^{89} \mathrm{Zr}\right] \mathrm{Zr}$-DFOIgG (10-11 MBq, 30-40 $\mu \mathrm{g})$ in 130-150 $\mu \mathrm{L}$ PBS via lateral tail-vein injections. PET whole-body acquisitions were recorded for mice at $24,48,72,96,120$, and $144 \mathrm{~h}$ post-injection using a dual microPET/CT scanner (Inveon, Siemens). Images were collected at $\geq 50 \mathrm{M}$ coincidence events per animal and reconstructed using standard OSEM 2D.

Biodistribution studies. Ex vivo gamma counting of tissues was performed to measure the uptake of the radioconjugate in tissues at $144 \mathrm{~h}$ post-radiotracer administration. Radioactivity contained within each organ was counted using a Perkin Elmer $y$-counter with isotopedependent calibrated protocols. Tracer uptake expressed as percentage injected dose per gram (\% ID/g) was calculated as the radioactivity associated with each tissue divided by the organ mass, using the mass of decay-corrected injected dose at the time of counting.

Statistical considerations. All data were analyzed by the unpaired, two-tailed Student $t$ test and differences at the $95 \%$ confidence level $(P<0.05)$ were considered statistically significant. Positive and negative controls were included whenever possible to ensure rigor and reproducibility throughout experimental design. 


\section{RESULTS}

Mass spectrometry analysis to identify MUC5AC target. To characterize the Ra96 antigen we performed secretome analyses. By immune detection of secretomes and lysates of the cell lines and by immune fluorescence analyses of pancreatic cancer cell lines, we selected the RA96 reactive and non-reactive cells. The cell line Capan-1 secreted the highest amounts of RA96 antigen, followed by A818, BxPC3 and Panc1. MiaPaCa2, Panctu II, Paca44 and the human pancreatic epithelial cells HPDE show no detectable reactivity for RA96 antibodies (Supplementary Figure 1). The RA96 antigen is a high molecular weight protein which is sensitive against reducing conditions and disappeared after treatment of the samples with dithiothreitol DTT. For mass spectrometry (MS) analysis, we chose Panctu II as the negative and the A818 cells as positive cells because of the more focused region in western blots than Capan-1. MS results were compiled in an additional file (see Supplementary Figure Series 2). Only MUC5AC was exclusively found with maximal five unique peptides in the secretome samples from RA96 reactive cell lines with or without immunoprecipitation (see Supplementary Materials for tables of MS results).

Immunoprecipitation confirms MUC5AC at RA96 target. In order to confirm the conclusion of the MS results, we performed immunoprecipitation with RA96 and in parallel with MUC5AC monoclonal antibody 2-11M1 (Biomol, Hamburg, Germany) in the same experiments (Supplementary Figure 3) and tested the immune complexes with the antibodies vice versa. The immune precipitated proteins isolated by $2-11 \mathrm{M} 1$ antibodies were recognized by RA96 antibodies, and the proteins immune precipitated by RA96 are also recognized by anti MUC5AC clone 2-11M1. A MUC5AC N-terminal peptide (Sigma-Aldrich) was used for competition of the RA96 immune signals in western blots. The signal intensity of 2-11M1 antibody could be reduced to $50 \%$ by the treatment with $10 \mu \mathrm{g} / \mathrm{ml} \mathrm{N}$-terminal peptide, whereas the treatment was not sufficient to significantly diminish the RA96 signals (data not shown). 
MUC5AC siRNA experiments and re-expression confirms RA96 specificity. We used siRNA on-target plus for knockdown of Muc5AC expression in positive cells (Supplementary Figure 4A, B). In western blots the RA96 signal intensity dropped down to the $20 \%$ of the untreated sample. To characterize the epitope of RA96 in more detail we performed MUC5AC re-expression experiments. The constructs were described by Ryan et al. (kindly provided to us by M. Clyne and C. Reid) and coding for MUC5AC (N-term, C-term and N+2TR+C-terminal fragments) were used in Cos7 control cells (12). RA96 and anti-MUC5AC 2-11M1 recognized the lysates of MUC5AC transfected cells with the $\mathrm{N}+2 \mathrm{TR}+\mathrm{C}$-construct and with the $\mathrm{N}$-term) (Supplementary Figure 4C). Neither RA96 nor 2-11M1 detected the C-terminal fragment. The expression of the C-terminal part in transfected COS7 cells was checked with the help of the flag tags on the $\mathrm{C}$ terminal construct (data not shown).

Immunohistochemistry with RA96 highlights specificity for PC lesions over CP. RA96 shows positive staining and a specific progression of severity in clinical samples. Positive staining begins at the PanIN level with increased staining in different grades of PDAC, including staining in capan-2 xenografts (Figure 1). There is little to no staining in the chronic pancreatitis samples, highlighting specificity for PC over other inflammatory conditions that are often conflated by serum biomarkers. Clinical IHC is tabulated and quantified in Supplementary Figure 5 (19).

[ ${ }^{89} \mathrm{Zr}$ Zr-DFO-RA96 shows significant tumor delineation in capan-2 xenografts. Multiple stoichiometric ratios $(10 \times, 20 \times$, and $40 \times)$ of chelator (DFO) to antibody (RA96 or IgG) were characterized via matrix-assisted light desorption ionization time-of-flight mass spectrometry (MALDI-ToF MS). Reactions conditions that resulted in DFO-RA96 and DFO-IgG with an average of 3-4 chelators/antibody were used in further radiolabeling procedures. All radiotracers were examined for their stability in serum each show $>95 \%$ stability out to one week for RA96 and $>90 \%$ stability for IgG radiolabeled constructs (Supplemental Figure 6). The radiochemical 
yield for each reaction ranged from $90-95 \%$ and all tracers used in vivo were processed to a radiochemical purity of $>99 \%$. The specific activity and molar activity for both [ ${ }^{89} \mathrm{Zr}$ ]Zr-DFO-RA96 and [ ${ }^{89} \mathrm{Zr}$ ]Zr-DFO-lgG was $0.3-0.4 \mathrm{MBq} / \mu \mathrm{g}$ and $45-55 \mathrm{GBq} / \mu \mathrm{mol}$, respectively. Serial PET imaging with [ $\left.{ }^{89} \mathrm{Zr}\right] \mathrm{Zr}$-DFO-RA96 shows significant uptake $(14.6 \pm 1.5 \% \mathrm{ID} / \mathrm{g})$ compared to the blocking group $(6.6 \pm 1.5 \% \mathrm{ID} / \mathrm{g})$ and $\left.{ }^{89} \mathrm{Zr}\right] \mathrm{Zr}$-DFO-IgG $(8.8 \pm 0.3 \% \mathrm{ID} / \mathrm{g})$, with a $\mathrm{P}<0.001$ for both. In capan-2 tumors, increased accumulation of antibody is observed over the course of 144 h (Figure 2), as expected for antibody-based radiotracers. In order to mitigate liver uptake for a shed serum biomarker, we tried the pre-injection strategy as previously described by Houghton et al. with anti-CA19-9 radiotracer (20). In order to mimic these studies, we pre-injected a $3 \times$ cold dose (unlabeled RA96) $4 \mathrm{~h}$ prior to [ ${ }^{89} \mathrm{Zr}$ ]Zr-DFO-RA96 administration. Interestingly, we observed a partial block of the system, with no statistical difference between [ $\left.{ }^{89} \mathrm{Zr}\right] \mathrm{Zr}$-DFO-RA96 tumor uptake via a $3 \times$ pre-injection or a $30 \times$ cold blocking dose co-injection $(6.2 \pm 0.8 \% \mathrm{ID} / \mathrm{g}$ for the $3 \times$ pre-injection vs. $6.6 \pm 1.5 \% \mathrm{ID} / \mathrm{g}$ for the $30 \times$ co-injection). The $30 \times$ dose was specifically administered for blocking purposes to confirm specificity of the RA96 tracer. The block and partial block groups, along with the $\left.{ }^{89} \mathrm{Zr}\right] \mathrm{Zr}$-DFO-IgG arm have a P-value of less than 0.001 when compared to the specific uptake of $\left.{ }^{89} \mathrm{Zr}\right] \mathrm{Zr}$-DFO-RA96 in the tumor (Figure 3). This can also be observed as early as $24 \mathrm{~h}$ and is consistent at $72 \mathrm{~h}$ as well (Supplemental Figures 7 and 8). We performed an ELISA experiment on serum samples collected from capan-2 mice one week prior to PET imaging experiments to assess the degree of MUC5AC antigen shedding in this model. We could not find any detectable MUC5AC in serum samples of these animals, despite the successful calibration curve and quality controls for the kit (Supplemental Figure 9). These results are consistent with our partial block of our target from the pre-injection of unlabeled antibody. 
$\left.{ }^{[89} \mathrm{Zr}\right] \mathrm{Zr}$-DFO-RA96 shows significant tumor delineation in orthotopic xenografts of varying MUC5AC expression. To further expand on the utility of this tracer, we inoculated animals orthotopically with tumors of varying MUC5AC expression and RA96 immunogenicity. We found that the uptake did indeed correlate with low, medium, and high-MUC5AC expressing tumors in orthotopic models of MIA PaCA-2, Capan-2, and Capan-1, respectively (Figure 4). Additional imaging of this cohort at $72 \mathrm{~h}$ can be found in Supplemental Figure 10.

\section{DISCUSSION}

With all of these data taken together, we were able to confirm that RA96 can demarcate MUC5AC expression in PC tumors. Our immuno-PET tracer [ $\left.{ }^{89} \mathrm{Zr}\right] \mathrm{Zr}$-DFO-RA96 shows excellent and specific tumor delineation in MUC5AC-positive tumors that can be blocked with both a partial and excess administration of unlabeled RA96. While the capan-2 tumor model has been characterized as a shed antigen model for serum biomarker CA19.9 (20), we did not observe significant shedding of MUC5AC, despite clinical data showing a similar effect of this secreted biomarker (9). Moreover, we also indicate that $\left.{ }^{89} \mathrm{Zr}\right] \mathrm{Zr}$-DFO-RA96 is able to detect orthotopic lesions in multiple models of PC of varying MUC5AC expression. Finally, RA96 is multipurposed in its ability to serve as an antibody for $\mathrm{IHC}$, successfully delineating $\mathrm{CP}$ from $\mathrm{PC}$ through staining of MUC5AC in PanINs and increasing grades of PDAC. We show strong evidence that this biomarker, antibody, and radiotracer has great potential for the field of PC diagnostics through multiple modalities.

Repeat biopsies are invasive and often lack reproducibility due to sampling issues, particularly in heterogenous tumors such as PC. More importantly, biopsies may not be particularly useful for patients with widespread metastases, which is often the case for PC. A whole-body imaging agent that is specific for PC over CP could serve as an early diagnostic for PanINs and would be a game-changing biomarker that serves to fulfill a diagnostic niche the 
field of PC is desperately missing. Currently, the standard for diagnostic imaging $P C$ in the clinic is typically CT or MRI. While these techniques can be sufficient for diagnostic purposes, CT and MRI do not offer all of the advantages that PET does in terms of quantitative measurement of a specific biomarker.

Establishing biomarkers in PC is a critically unmet need in order to improve the prognosis of this challenging disease. Although several diagnostic biomarkers for PC have been investigated, the majority of these have yielded suboptimal results (21-23). CA19-9, a blood based biomarker for follow-up is useful for disease prognosis, but it has limited utility as an early detection marker due to its variable sensitivity (60-90\%), specificity (68-91\%), and positive predictive value $(0.9-2.4 \%)(24,25)$. Additionally, CA19-9 can be elevated in benign conditions such as CP, jaundice, and cirrhosis. Furthermore, approximately $5-10 \%$ of Caucasians are unable to synthesize CA19-9 (25-27), which makes it challenging for widespread reliability as a biomarker in the clinic. Approximately $65 \%$ of resectable PC cases have elevated levels of CA19-9 in the blood (21). In light of the sporadic nature of PC and asymptomatic early disease stages, identification and characterization of serum markers that can either complement or outperform CA19-9 is highly desirable.

Previous studies have shown that CA19-9 levels can predict stage and survival in resectable PC (28) and well as locally unresectable PC (29). Multiple recent studies have also revealed the non-specific nature of CA19-9 as a diagnostic marker $(2-4,30)$. Several promising studies focus on CA19-9 for both imaging and radioimmunotherapy $(31,32)$ and are ongoing at MSK. We aim to apply our expertise in order to evaluate novel biomarkers for both early and specific detection of PC and to drive the improvement of clinical outcomes for this devastating disease. Clinical "gold standard" metabolic radiotracers such as $\left[{ }^{18} \mathrm{~F}\right]$ fluorodeoxyglucose ( $\left.\left[{ }^{18} \mathrm{~F}\right] \mathrm{FDG}\right)$ are often nonspecific for malignancy (33). Our MUC5AC-targeted radiotracer could 
fill the gap that exists for serum biomarkers and serve to fulfill an unmet need for early diagnosis in PC.

\section{CONCLUSION}

Current biomarkers for PC are unreliable when it comes to differentiating between inflammation and malignancy. The RA96 antibody has been well-characterized to be a MUC5AC conformation-dependent antigen. RA96 has the ability to achieve early detection for PC as it can detect lesions from PanINs all the way to fully developed PDAC via IHC, as well as specifically demarcate PC from CP in patient samples. We have successfully developed an immuno-PET tracer with RA96 and shown that it can noninvasively and specifically demarcate MUC5AC expression in PC. We expect that immuno-PET targeting MUC5AC has high potential to be clinically useful for early detection of PC.

\section{DISCLOSURES}

The authors have declared that no conflict of interest exists.

\section{ACKNOWLEDGEMENTS}

We gratefully acknowledge the Antibody \& Bioresource, Small Animal Imaging, and the Radiochemistry and Molecular Imaging Probe Core Facilities at MSK, all of which are supported in part by $\mathrm{NIH}$ grant P30 CA08748. We acknowledge BioRender for the preparation of the graphical abstract. We acknowledge Mr. William H. Goodwin and Mrs. Alice Goodwin and the Commonwealth Foundation for Cancer Research and The Experimental Therapeutics Center of MSK (J.G.). We would also like to acknowledge financial support from NIH grant R35 CA232130-

01A1 (J.S.L.) and the MSK Center for Molecular Imaging and Nanotechnology Tow Fellowship (K.E.H.). A part of this study was funded by P.U.R.E. (Protein Research Unit Ruhr within 
Europe), Ministry of Innovation, Science and Research of North-Rhine Westphalia, Germany. This work is dedicated to the late Prof. Siegfried Matzku, DKFZ, Heidelberg, Germany, who initiated in vivo targeting strategies decades ago. We also sincerely appreciate the long-standing support of Prof. Günter Klöppel, now Pathology Munich, who helped to select the best candidates from an overwhelming number of hybridoma cultures during the common projects in Hamburg.

\section{KEY POINTS}

QUESTION: The central hypothesis of this study is that our MUC5AC-targeted antibody RA96 could detect PC lesions that are specific from other instances of inflammation such as CP.

PERTINENT FINDINGS: We demonstrate that our immuno-PET strategy can be used to noninvasively detect MUC5AC expression in PC, a key serum biomarker that is able to not only detect PanINs, but specifically demarcate PC from CP.

IMPLICATIONS FOR PATIENT CARE: There is a critical need for developing better biomarkers to improve early detection of pancreatic cancer $(\mathrm{PC})$. Current biomarkers for $\mathrm{PC}$ are unreliable when it comes to differentiating between inflammation and malignancy. [ ${ }^{89} \mathrm{Zr}$ ]Zr-DFO-RA96 could be a valuable tool to specifically demarcate PC from CP and detect early onset PanINs. 


\section{REFERENCES}

1. McGuigan A, Kelly P, Turkington RC, Jones C, Coleman HG, McCain RS. Pancreatic cancer: A review of clinical diagnosis, epidemiology, treatment and outcomes. World journal of gastroenterology. 2018;24(43):4846-61. doi: 10.3748/wjg.v24.i43.4846. PubMed PMID: 30487695.

2. $\quad$ Song J, Sokoll LJ, Pasay JJ, Rubin AL, Li H, Bach DM, Chan DW, Zhang Z. Identification of Serum Biomarker Panels for the Early Detection of Pancreatic Cancer. Cancer Epidemiology Biomarkers \&amp; Prevention. 2019;28(1):174-82. doi: 10.1158/1055-9965.Epi18-0483.

3. Ballehaninna UK, Chamberlain RS. Serum CA 19-9 as a Biomarker for Pancreatic Cancer-A Comprehensive Review. Indian J Surg Oncol. 2011;2(2):88-100. Epub 2011/02/17. doi: 10.1007/s13193-011-0042-1. PubMed PMID: 22693400.

4. Ballehaninna UK, Chamberlain RS. The clinical utility of serum CA 19-9 in the diagnosis, prognosis and management of pancreatic adenocarcinoma: An evidence based appraisal. Journal of gastrointestinal oncology. 2012;3(2):105-19. doi: 10.3978/j.issn.20786891.2011.021. PubMed PMID: 22811878.

5. Kato S, Hokari R, Crawley S, Gum J, Ahn D-H, Kim J-W, Kwon S-W, Miura S, Basbaum $\mathrm{C}, \mathrm{Kim} \mathrm{Y}$. MUC5AC mucin gene regulation in pancreatic cancer cells. Int $\mathrm{J}$ Oncol. 2006;29(1):33-40.

6. Rachagani S, Torres MP, Kumar S, Haridas D, Baine M, Macha MA, Kaur S, Ponnusamy MP, Dey P, Seshacharyulu P, Johansson SL, Jain M, Wagner K-U, Batra SK. Mucin (Muc) expression during pancreatic cancer progression in spontaneous mouse model: potential implications for diagnosis and therapy. Journal of Hematology \& Oncology. 2012;5(1):68. doi: 10.1186/1756-8722-5-68.

7. lacobuzio-Donahue CA, Velculescu VE, Wolfgang CL, Hruban RH. Genetic Basis of Pancreas Cancer Development and Progression: Insights from Whole-Exome and WholeGenome Sequencing. Clinical Cancer Research. 2012;18(16):4257-65. doi: 10.1158/10780432.Ccr-12-0315.

8. Matull WR, Andreola F, Loh A, Adiguzel Z, Deheragoda M, Qureshi U, Batra SK, Swallow DM, Pereira SP. MUC4 and MUC5AC are highly specific tumour-associated mucins in biliary tract cancer. British Journal of Cancer. 2008;98(10):1675-81. doi: 10.1038/sj.bjc.6604364.

9. Kaur S, Smith LM, Patel A, Menning M, Watley DC, Malik SS, Krishn SR, Mallya K, Aithal A, Sasson AR, Johansson SL, Jain M, Singh S, Guha S, Are C, Raimondo M, Hollingsworth MA, Brand RE, Batra SK. A Combination of MUC5AC and CA19-9 Improves the Diagnosis of Pancreatic Cancer: A Multicenter Study. Am J Gastroenterol. 2017;112(1):17283. Epub 2016/11/15. doi: 10.1038/ajg.2016.482. PubMed PMID: 27845339.

10. Kim GE, Bae HI, Park HU, Kuan SF, Crawley SC, Ho JJL, Kim YS. Aberrant expression of MUC5AC and MUC6 gastric mucins and sialyl Tn antigen in intraepithelial neoplasms of the 
pancreas. Gastroenterology. 2002;123(4):1052-60. doi:

https://doi.org/10.1053/gast.2002.36018.

11. Adamczyk KA, Klein-Scory S, Tehrani MM, Warnken U, Schmiegel W, Schnölzer M, Schwarte-Waldhoff I. Characterization of soluble and exosomal forms of the EGFR released from pancreatic cancer cells. Life Sciences. 2011;89(9):304-12. doi: https://doi.org/10.1016/j.Ifs.2011.06.020.

12. Ryan A, Smith A, Moore P, McNally S, Carrington SD, Reid CJ, Clyne M. Expression and Characterization of a Novel Recombinant Version of the Secreted Human Mucin MUC5AC in Airway Cell Lines. Biochemistry. 2015;54(4):1089-99. doi: 10.1021/bi5011267.

13. Nollet S, Escande F, Buisine MP, Forgue-Lafitte ME, Kirkham P, Okada Y, Bara J. Mapping of SOMU1 and M1 Epitopes on the Apomucin Encoded by the 5' End of the MUC5AC Gene. Hybridoma and Hybridomics. 2004;23(2):93-9. doi: 10.1089/153685904774129694.

14. Witzke KE, Rosowski K, Müller C, Ahrens M, Eisenacher M, Megger DA, Knobloch J, Koch A, Bracht T, Sitek B. Quantitative Secretome Analysis of Activated Jurkat Cells Using Click Chemistry-Based Enrichment of Secreted Glycoproteins. Journal of Proteome Research. 2017;16(1):137-46. doi: 10.1021/acs.jproteome.6b00575.

15. Kalthoff H, Schmiegel, W.-H., Auerswald, U., Matzku, S., Klöppel, G., Holl, K., Greten, H., Thiele, H.-G. Monoclonal antibody RA-96 defines a new mucin antigen in pancreatic cancer. Digestion. 1988;40(90).

16. Neesse A, Hahnenkamp A, Griesmann H, Buchholz M, Hahn SA, Maghnouj A, Fendrich V, Ring J, Sipos B, Tuveson DA, Bremer C, Gress TM, Michl P. Claudin-4-targeted optical imaging detects pancreatic cancer and its precursor lesions. Gut. 2013;62(7):1034-43. doi: 10.1136/gutjnl-2012-302577.

17. Henry KE, Dacek MM, Dilling TR, Caen JD, Fox IL, Evans MJ, Lewis JS. A PET Imaging Strategy for Interrogating Target Engagement and Oncogene Status in Pancreatic Cancer. Clinical Cancer Research. 2018.

18. Holland JP, Sheh Y, Lewis JS. Standardized methods for the production of high specific-activity zirconium-89. Nuclear medicine and biology. 2009;36(7):729-39. doi: 10.1016/j.nucmedbio.2009.05.007. PubMed PMID: PMC2827875.

19. Juhl H, Stritzel M, Wroblewski A, Henne-Bruns D, Kremer B, Schmiegel W, Neumaier $\mathrm{M}$, Wagener $\mathrm{C}$, Schreiber $\mathrm{H}-\mathrm{W}$, Kalthoff $\mathrm{H}$. Immunocytological detection of micrometastatic cells: Comparative evaluation of findings in the peritoneal cavity and the bone marrow of gastric, colorectal and pancreatic cancer patients. International Journal of Cancer. 1994;57(3):330-5. doi: 10.1002/ijc.2910570307.

20. Houghton JL, Abdel-Atti D, Scholz WW, Lewis JS. Preloading with Unlabeled CA19.9 Targeted Human Monoclonal Antibody Leads to Improved PET Imaging with 89Zr-5B1. Molecular Pharmaceutics. 2017;14(3):908-15. doi: 10.1021/acs.molpharmaceut.6b01130.

21. Goggins M. Molecular Markers of Early Pancreatic Cancer. Journal of Clinical Oncology. 2005;23(20):4524-31. doi: 10.1200/JCO.2005.19.711. 
22. Kaur S, Baine MJ, Jain M, Sasson AR, Batra SK. Early diagnosis of pancreatic cancer: challenges and new developments. Biomark Med. 2012;6(5):597-612. doi:

10.2217/bmm.12.69. PubMed PMID: 23075238.

23. Koopmann J, Rosenzweig CNW, Zhang Z, Canto MI, Brown DA, Hunter M, Yeo C, Chan DW, Breit SN, Goggins M. Serum Markers in Patients with Resectable Pancreatic Adenocarcinoma: Macrophage Inhibitory Cytokine 1 versus CA19-9. Clinical Cancer Research. 2006;12(2):442-6. doi: 10.1158/1078-0432.Ccr-05-0564.

24. Locker GY, Hamilton S, Harris J, Jessup JM, Kemeny N, Macdonald JS, Somerfield MR, Hayes DF, Bast RC. ASCO 2006 Update of Recommendations for the Use of Tumor Markers in Gastrointestinal Cancer. Journal of Clinical Oncology. 2006;24(33):5313-27. doi: 10.1200/JCO.2006.08.2644.

25. Duffy MJ, Sturgeon C, Lamerz R, Haglund C, Holubec VL, Klapdor R, Nicolini A, Topolcan O, Heinemann V. Tumor markers in pancreatic cancer: a European Group on Tumor Markers (EGTM) status report. Annals of Oncology. 2009;21(3):441-7. doi:

10.1093/annonc/mdp332.

26. Brody JR, Witkiewicz AK, Yeo CJ. The Past, Present, and Future of Biomarkers: A Need for Molecular Beacons for the Clinical Management of Pancreatic Cancer. Advances in Surgery. 2011;45(1):301-21. doi: https://doi.org/10.1016/j.yasu.2011.04.002.

27. Ghaneh P, Costello E, Neoptolemos JP. Biology and management of pancreatic cancer. Postgraduate Medical Journal. 2008;84(995):478-97. doi: 10.1136/gut.2006.103333.

28. Ferrone CR, Finkelstein DM, Thayer SP, Muzikansky A, Fernandez-delCastillo C, Warshaw AL. Perioperative CA19-9 levels can predict stage and survival in patients with resectable pancreatic adenocarcinoma. Journal of clinical oncology : official journal of the American Society of Clinical Oncology. 2006;24(18):2897-902. doi:

10.1200/JCO.2005.05.3934. PubMed PMID: 16782929.

29. Yang GY, Malik NK, Chandrasekhar R, Ma W-W, Flaherty L, lyer R, Kuvshinoff B, Gibbs J, Wilding G, Warren G, May KS. Change in CA 19-9 levels after chemoradiotherapy predicts survival in patients with locally advanced unresectable pancreatic cancer. Journal of Gastrointestinal Oncology. 2013;4(4):361-9.

30. Wong S-J, Hong C-M, Wang H-P, Cheng T-Y. High Serum Level of CA 19-9 not Always Related to the Pancreas: An Asymptomatic Case of Highly Elevated CA 19-9 Related to Lung Adenocarcinoma. Journal of the Pancreas. 2016.

31. Lohrmann C, O'Reilly EM, O'Donoghue JA, Pandit-Taskar N, Carrasquillo JA, Lyashchenko SK, Ruan S, Teng R, Scholz W, Maffuid PW, Lewis JS, Weber WA. Retooling a Blood-Based Biomarker: Phase I Assessment of the High-Affinity CA19-9 Antibody HuMab5B1 for Immuno-PET Imaging of Pancreatic Cancer. Clinical Cancer Research. 2019;25(23):7014-23. doi: 10.1158/1078-0432.Ccr-18-3667.

32. Poty S, Carter LM, Mandleywala K, Membreno R, Abdel-Atti D, Ragupathi A, Scholz WW, Zeglis BM, Lewis JS. Leveraging bioorthogonal click chemistry to improve 225Ac- 
radioimmunotherapy of pancreatic ductal adenocarcinoma. Clinical Cancer Research. 2018:clincanres.1650.2018. doi: 10.1158/1078-0432.Ccr-18-1650.

33. Ibrahim N, Cho S, Hall L, Perlman S. Is it cancer? Potential pitfalls of FDG PET/CT imaging. Journal of Nuclear Medicine. 2016;57(supplement 2):1315. 

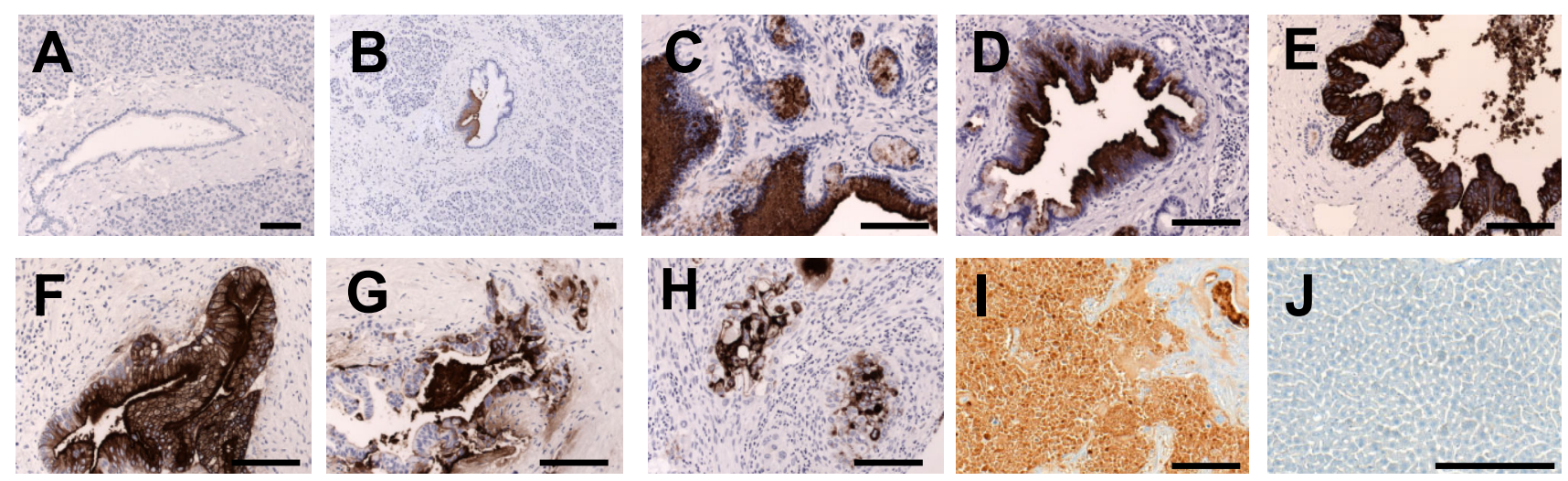

Figure 1. Immunohistochemistry of MUC5AC with RA96. A. No expression of RA96 in normal human pancreas. B. No or weak expression in chronic pancreatitis. C-E. Strong staining with RA96 in pancreatic intraepithelial neoplasia 1-3. F-H. Moderate to strong expression in pancreatic ductal adenocarcinoma of different grades. More detail is provided in the Supplementary Materials with regard to grade and scoring. I. Capan-2 xenografts were also positive with RA96. J. Control tissue shows no background staining in the liver. Each line indicates $50 \mu \mathrm{m}$. 


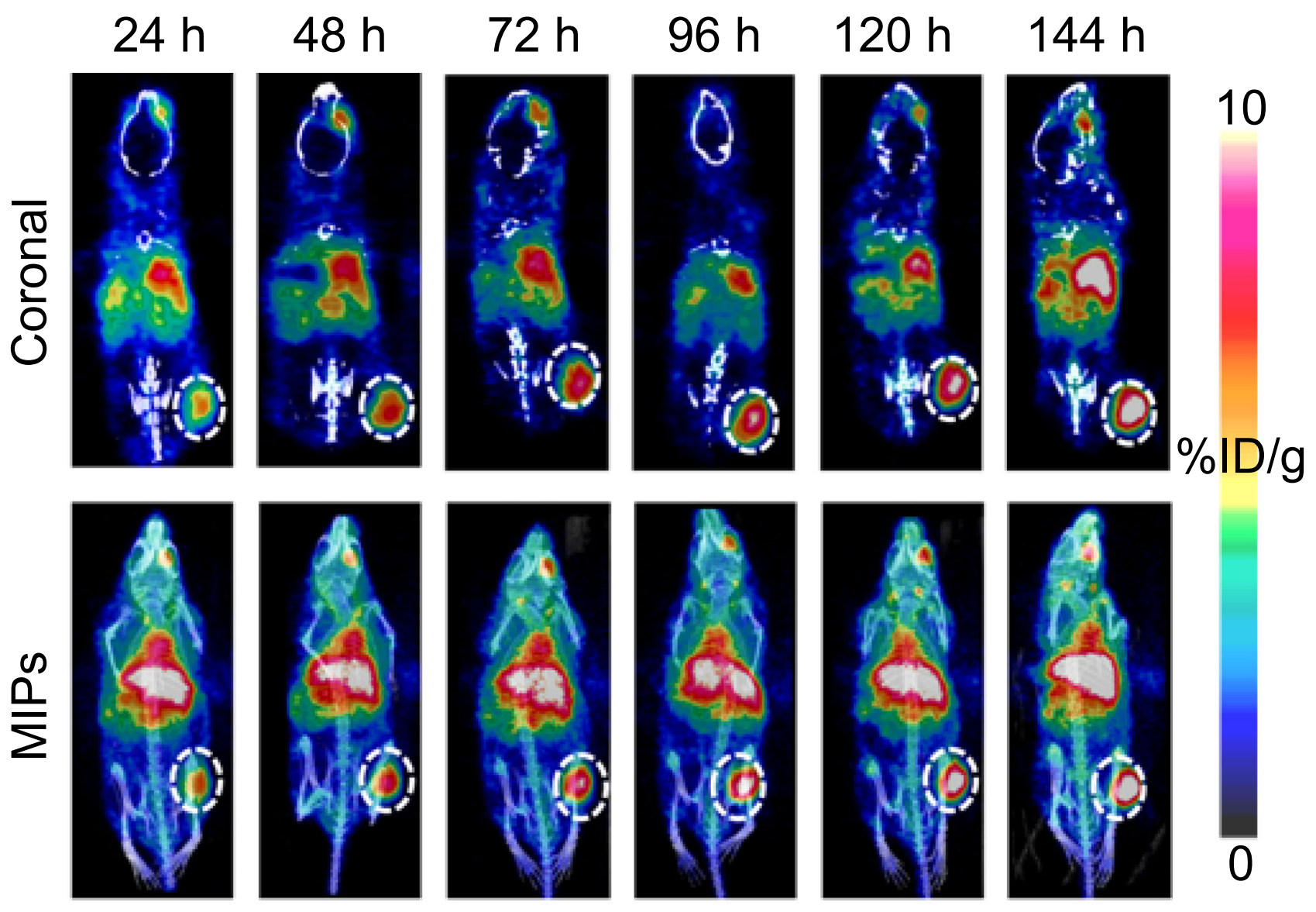

Figure 2. Serial PET/CT imaging of [ $\left.{ }^{89} \mathrm{Zr}\right] \mathrm{Zr}$-DFO-RA96 over the course of $144 \mathrm{~h}$. Images are represented as coronal slices $(A)$ and maximum intensity projections $(B)$. Tumors are on the right flank and indicated by the dotted line. Mice were retro-orbitally bled from the right eye one week prior, resulting in non-specific uptake of the radiotracer in the eye region. Increasing uptake of the radiotracer in the tumor is shown over time, with the maximum at $144 \mathrm{~h}$. 

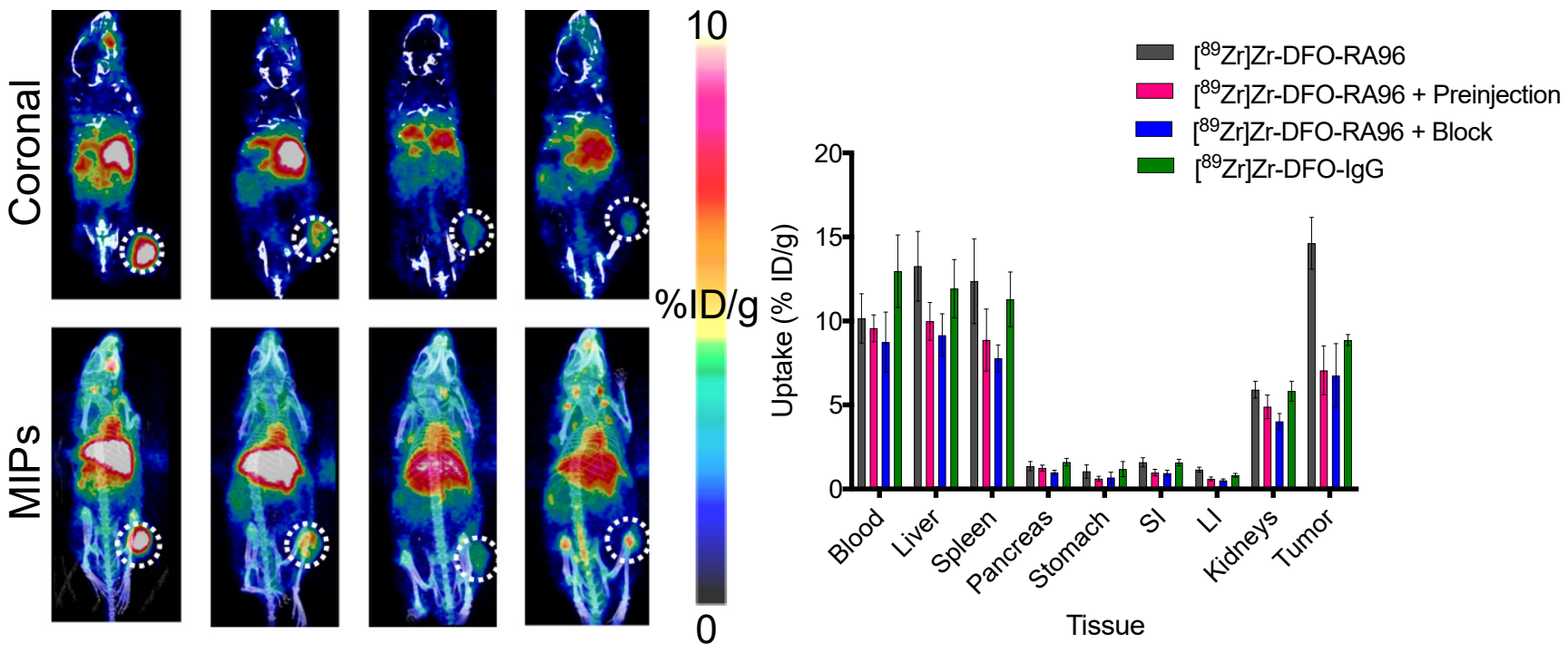

Figure 3. Serial PET/CT imaging of $\left[{ }^{89} \mathrm{Zr}\right] \mathrm{Zr}-\mathrm{DFO}-\mathrm{RA} 96$ and $\left.{ }^{89} \mathrm{Zr}\right] \mathrm{Zr}$-DFO-IgG with corresponding ex vivo biodistribution at $\mathbf{1 4 4} \mathrm{h}$. Images are represented as coronal slices (A) and maximum intensity projections (B). Tumors are on the right flank and indicated by the dotted line. Significant differences are noted when comparing the $\left.{ }^{89} \mathrm{Zr}\right] \mathrm{Zr}$-DFO-RA96 to all control groups $(P<0.001)$. Pre-injection: indicates a partial block, with $3 \times$ amount of unlabeled antibody injected $4 \mathrm{~h}$ prior to injection with [ ${ }^{89} \mathrm{Zr}$ ]Zr-DFO-RA96. Block: full block with $30 \times$ amount of unlabeled antibody coinjected with [ ${ }^{89}$ Zr]Zr-DFO-RA96. IgG: injection of isotype-matched control [ $\left.{ }^{89} \mathrm{Zr}\right] \mathrm{Zr}$-DFO-IgG. Mice were retro-orbitally bled from the right eye one week prior, resulting in non-specific uptake of radiotracer in the eye region. 

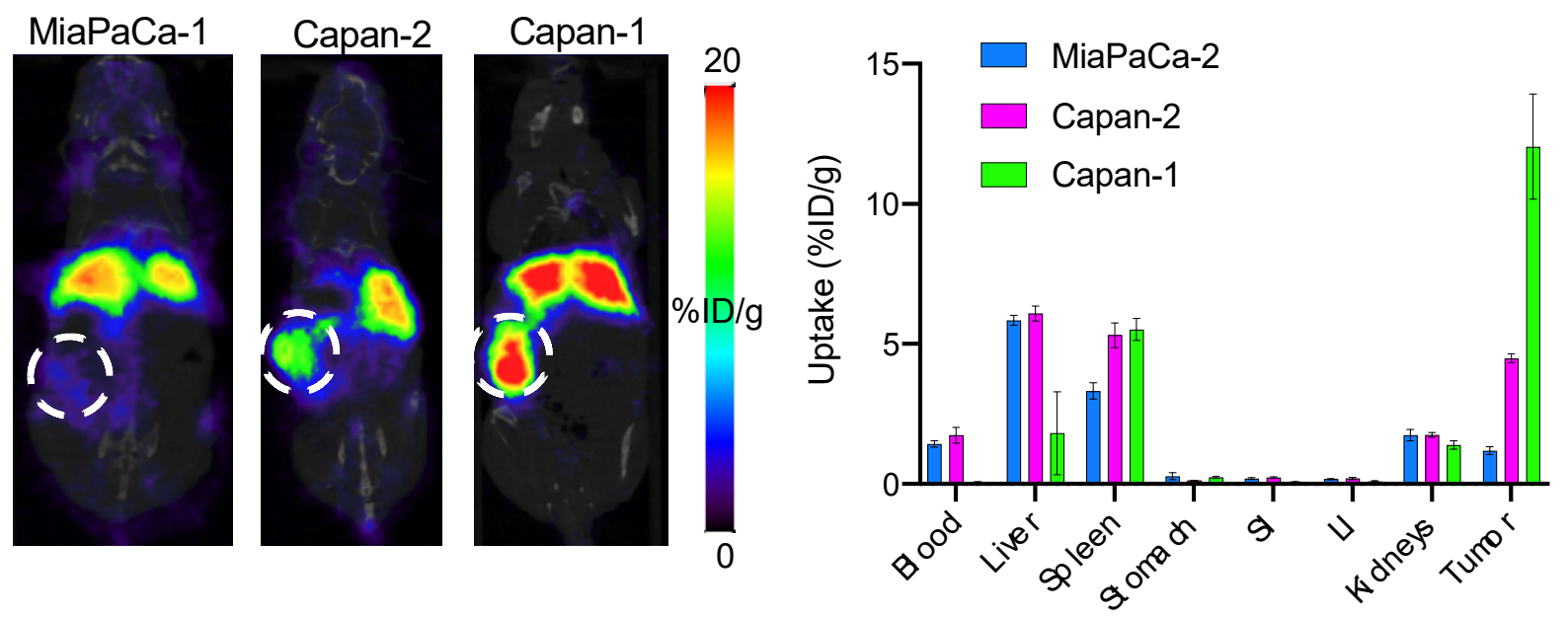

Figure 4. PET/CT imaging of $\left[{ }^{89} \mathrm{Zr}\right] \mathrm{Zr}$-DFO-RA96 with corresponding ex vivo biodistribution at $144 \mathrm{~h}$ in multiple orthotopic tumor models. Images are represented as coronal slices and tumors are indicated by white circles. From left to right: MiaPaCa-1 tumors (low MUC5AC expression), Capan-2 tumors (medium MUC5AC expression), and Capan-1 tumors (high MUC5AC expression), with corresponding ex vivo biodistribution. 


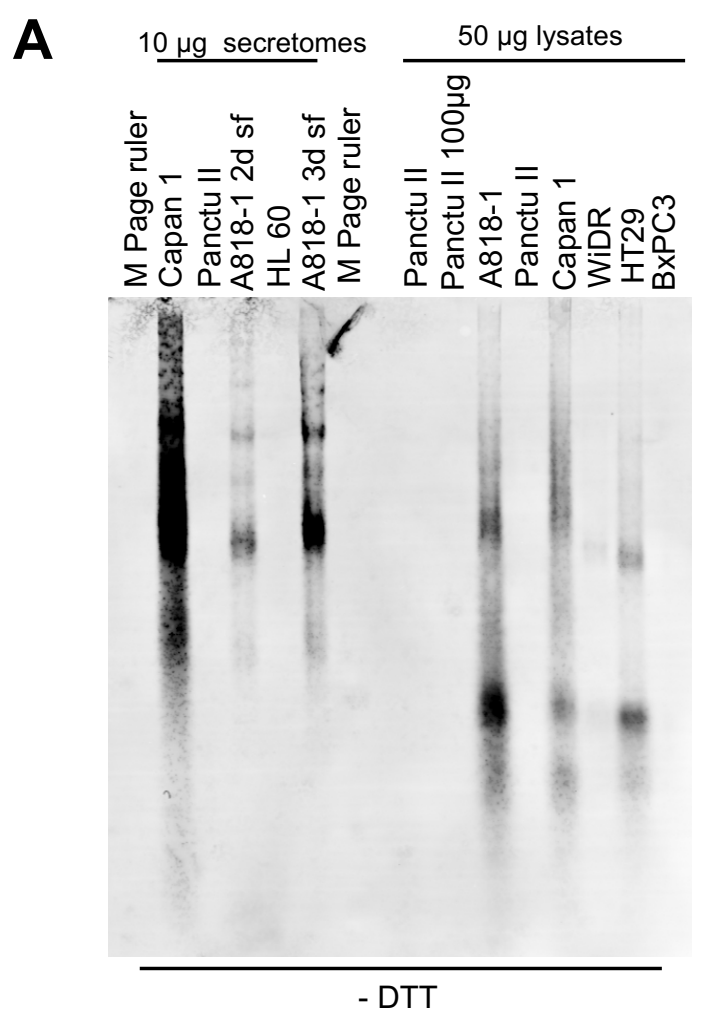

WB: RA96 monoclonal antibody

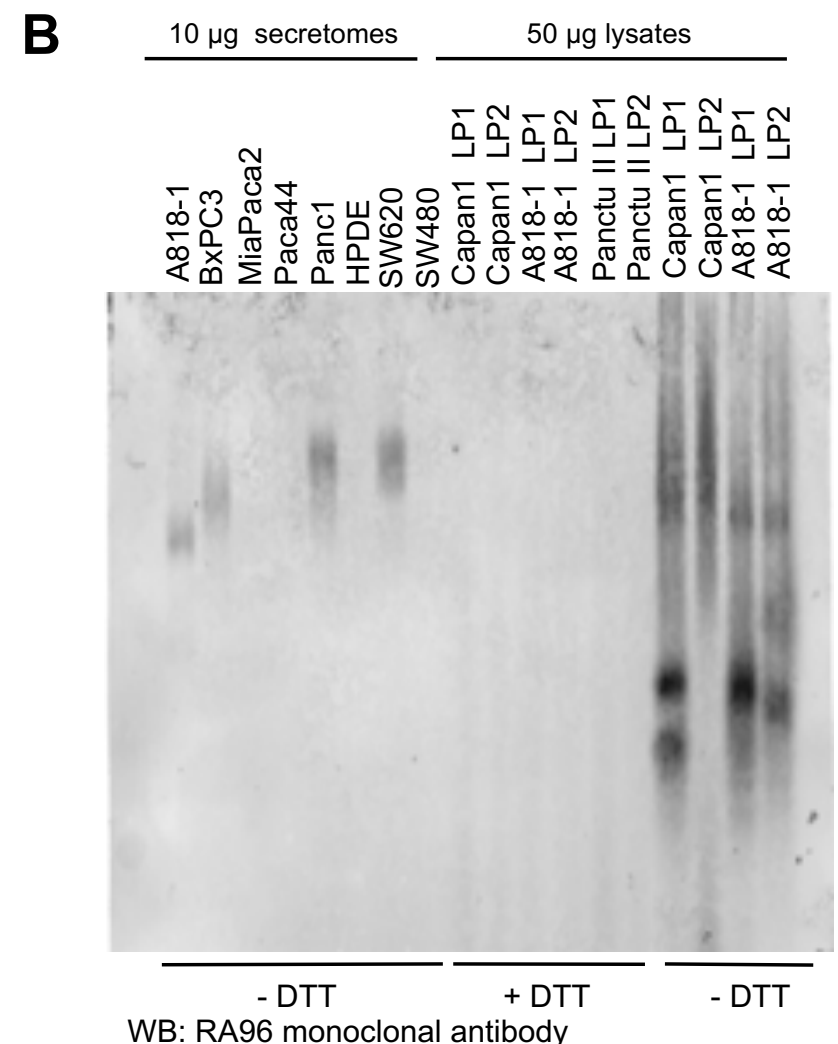

WB: RA96 monoclonal antibody

Supplementary Figure 1. Agarose gel separated samples of pancreatic and colorectal cancer cells were analyzed by western blots. Capan secretome highly expressed MUC5AC antigen. The RA96 antigen is only detectable if samples are not reduced (-DTT). Negative epithelial cell lines are Panctu II, Paca44, MiaPaca2, HPDE, SW480, whereas RA96 positive are Capan-1, A818, Panc1, BxPC3, HT29, WiDR, SW620. 
Supplementary Table 1. Summary of antigen characterization results. Agarose gel pieces bearing reactive RA96 antigens were excised and subjected to the mass spectrometry procedure. The loaded whole protein amount, the maximum of the score and the sum of identified peptides to the identifications were given.

\begin{tabular}{|c|c|c|c|c|c|c|c|c|c|c|}
\hline \multicolumn{11}{|l|}{ Experiment A } \\
\hline Sample & $\mu \mathrm{g}$ & Lane & $\begin{array}{c}\text { reactive } \\
\text { band }\end{array}$ & \# Ids & $\begin{array}{c}\text { max \# peps } \\
\text { per ID }\end{array}$ & $\begin{array}{c}\text { Sum \# } \\
\text { Unique } \\
\text { peptides }\end{array}$ & $\begin{array}{c}\text { sum \# } \\
\text { peps }\end{array}$ & $\begin{array}{c}\text { score } \\
\text { max }\end{array}$ & $\begin{array}{c}\text { \# Muc5AC } \\
\text { unique } \\
\text { peptides }\end{array}$ & $\begin{array}{c}\text { Muc5AC } \\
\text { score } \\
\max \end{array}$ \\
\hline PC secretome B3 & 10 & 3 & B3 & 149 & 8 & 95 & 307 & 510,99 & 5 & 141,11 \\
\hline NC secretome B3 & 10 & 4 & B3 & 71 & 2 & 15 & 95 & 189,88 & 0 & - \\
\hline \multicolumn{11}{|l|}{ Experiment B } \\
\hline IP PC Secr B2 & 40 & 2 & B2 & 79 & 5 & 115 & 123 & 182,22 & 2 & 54,74 \\
\hline IP PC lysate B3 & 200 & 4 & B3 & 203 & 30 & 395 & 426 & 875,64 & 17 & 590,06 \\
\hline PC Secreme B2 & 10 & 8 & B2 & 112 & 4 & 159 & 168 & 319,16 & 1 & 23,23 \\
\hline PC lysate B3 & 50 & 6 & B3 & 675 & 57 & 1614 & 1720 & 2385,57 & 13 & 427,13 \\
\hline
\end{tabular}


Supplementary Figure Series 2. Annotated spectra and fragment ion series for identified peptides corresponding to Mucin 5AC (MUC5AC). In the spectra the precursor ion is depicted in green, $b$ ions in red and $y$ ions in blue, respectively. Tables show the $b$ and $y$ ion series with the theoretical mass to charge ratios $(\mathrm{m} / \mathrm{z})$ that were assigned to the recorded spectra. Assigned fragment ions are highlighted in red for $b$ and blue for $y$ ions, respectively.

AEDAPGVPLR (q-value $=0$, Mascot ion score $=24$, Exp. value $=1.2 \mathrm{E}-002)$

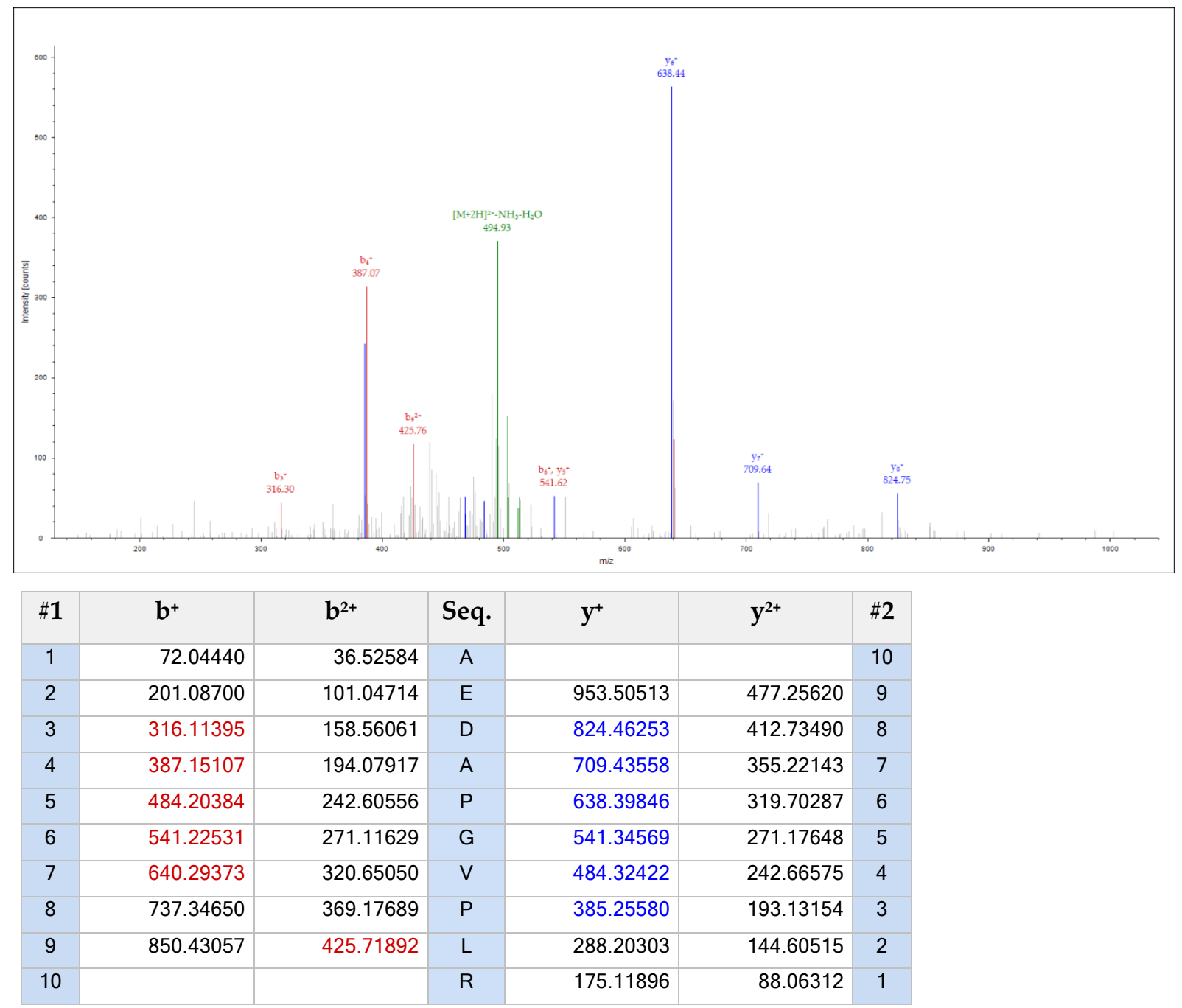


GTDSGDFDTLENLR $(\mathrm{q}-\mathrm{value}=0$, Mascot ion score $=81$, Exp. value $=4.6 \mathrm{E}-008)$

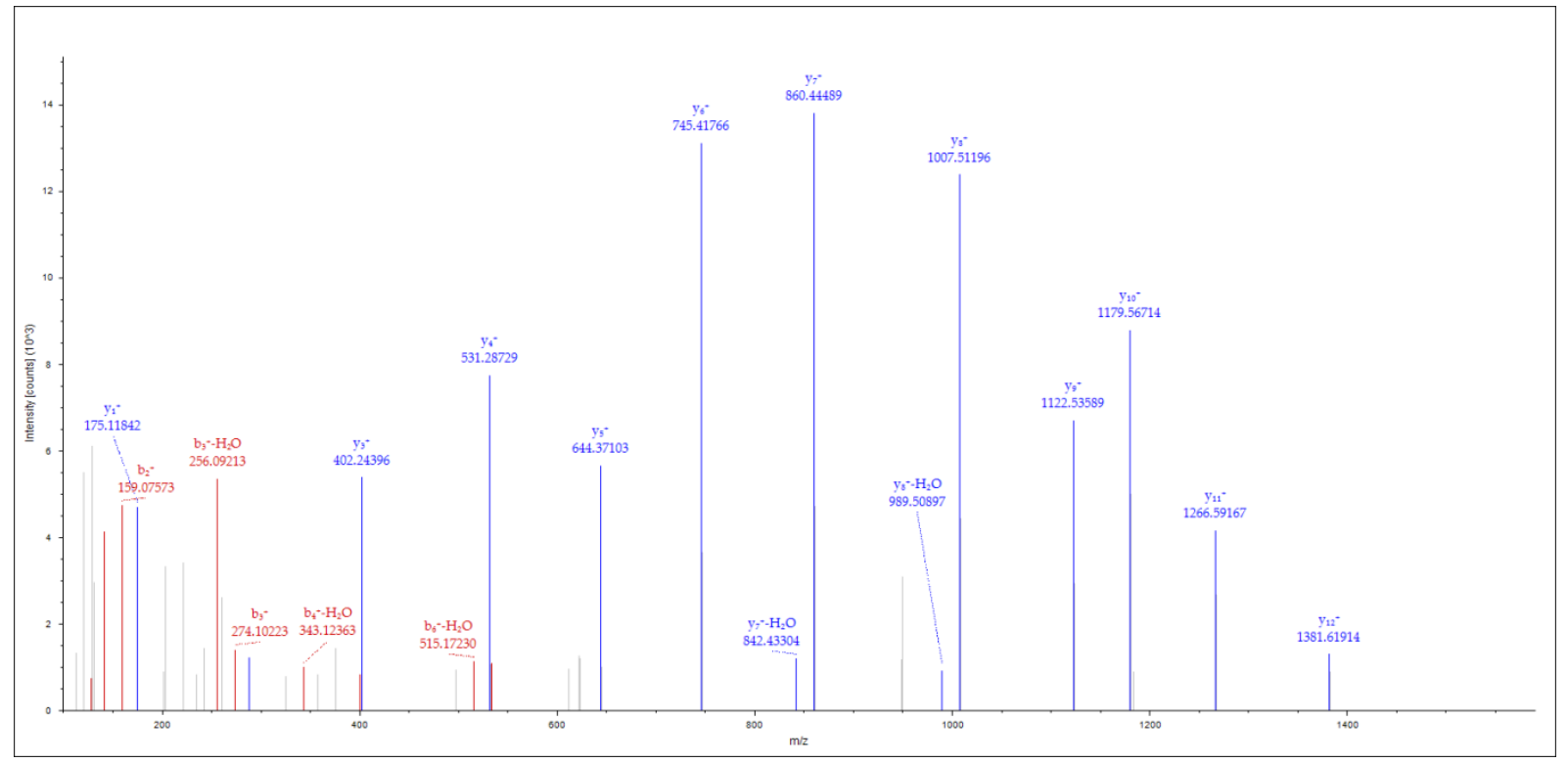

\begin{tabular}{|c|c|c|c|c|c|c|}
\hline$\# 1$ & $\mathbf{b}^{+}$ & $b^{2+}$ & Seq. & $\mathbf{y}^{+}$ & $\mathrm{y}^{2+}$ & $\# 2$ \\
\hline 1 & 58.02875 & 29.51801 & G & & & 14 \\
\hline 2 & 159.07643 & 80.04185 & $\mathrm{~T}$ & 1482.67076 & 741.83902 & 13 \\
\hline 3 & 274.10338 & 137.55533 & D & 1381.62308 & 691.31518 & 12 \\
\hline 4 & 361.13541 & 181.07134 & S & 1266.59613 & 633.80170 & 11 \\
\hline 5 & 418.15688 & 209.58208 & G & 1179.56410 & 590.28569 & 10 \\
\hline 6 & 533.18383 & 267.09555 & D & 1122.54263 & 561.77495 & 9 \\
\hline 7 & 680.25225 & 340.62976 & $\mathrm{~F}$ & 1007.51568 & 504.26148 & 8 \\
\hline 8 & 795.27920 & 398.14324 & D & 860.44726 & 430.72727 & 7 \\
\hline 9 & 896.32688 & 448.66708 & $\mathrm{~T}$ & 745.42031 & 373.21379 & 6 \\
\hline 10 & 1009.41095 & 505.20911 & L & 644.37263 & 322.68995 & 5 \\
\hline 11 & 1138.45355 & 569.73041 & $\mathrm{E}$ & 531.28856 & 266.14792 & 4 \\
\hline 12 & 1252.49648 & 626.75188 & $\mathrm{~N}$ & 402.24596 & 201.62662 & 3 \\
\hline 13 & 1365.58055 & 683.29391 & L & 288.20303 & 144.60515 & 2 \\
\hline 14 & & & $\mathrm{R}$ & 175.11896 & 88.06312 & 1 \\
\hline
\end{tabular}


SQESAAPTLSR $(\mathrm{q}-\mathrm{value}=0$, Mascot ion score $=41$, Exp. value $=7.0 \mathrm{E}-004)$

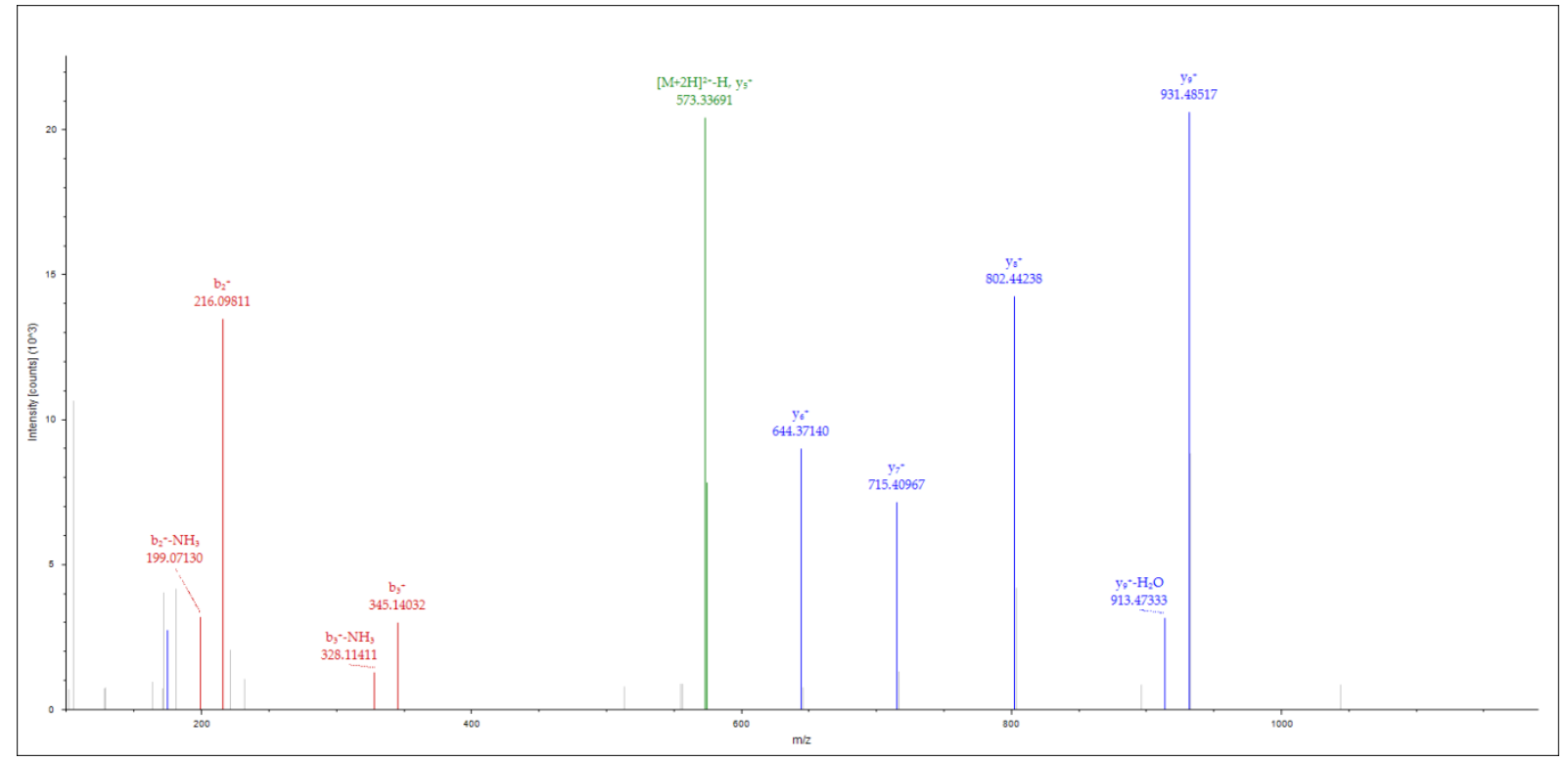

\begin{tabular}{|r|r|r|r|r|r|r|}
\hline$\# \mathbf{1}$ & $\mathbf{b}^{+}$ & $\mathbf{b}^{\mathbf{2 +}}$ & $\mathbf{S e q}$ & $\mathbf{y}^{+}$ & $\mathbf{y}^{\mathbf{2 +}}$ & $\# \mathbf{2}$ \\
\hline 1 & 88.03931 & 44.52329 & $\mathrm{~S}$ & & & 11 \\
\hline 2 & 216.09789 & 108.55258 & $\mathrm{Q}$ & 1059.54296 & 530.27512 & 10 \\
\hline 3 & 345.14049 & 173.07388 & $\mathrm{E}$ & 931.48438 & 466.24583 & 9 \\
\hline 4 & 432.17252 & 216.58990 & $\mathrm{~S}$ & 802.44178 & 401.72453 & 8 \\
\hline 5 & 503.20964 & 252.10846 & $\mathrm{~A}$ & 715.40975 & 358.20851 & 7 \\
\hline 6 & 574.24676 & 287.62702 & $\mathrm{~A}$ & 644.37263 & 322.68995 & 6 \\
\hline 7 & 671.29953 & 336.15340 & $\mathrm{P}$ & 573.33551 & 287.17139 & 5 \\
\hline 8 & 772.34721 & 386.67724 & $\mathrm{~T}$ & 476.28274 & 238.64501 & 4 \\
\hline 9 & 885.43128 & 443.21928 & $\mathrm{~L}$ & 375.23506 & 188.12117 & 3 \\
\hline 10 & 972.46331 & 486.73529 & $\mathrm{~S}$ & 262.15099 & 131.57913 & 2 \\
\hline 11 & & & $\mathrm{R}$ & 175.11896 & 88.06312 & 1 \\
\hline
\end{tabular}


NQDQQGPFK $(q-$ value $=0$, Mascot ion score $=38$, Exp. value $=1.5 \mathrm{E}-003)$

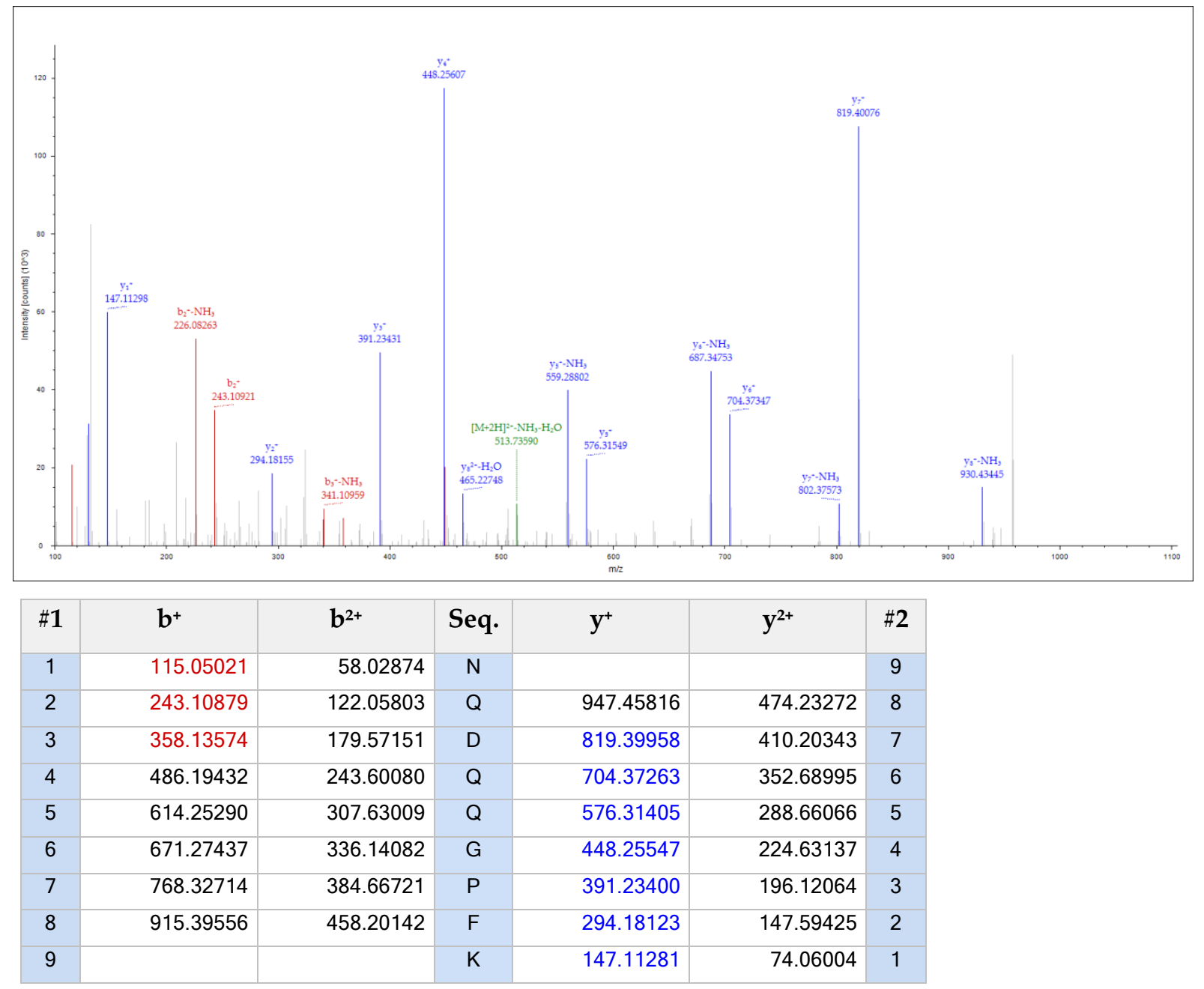


RPEEITR $(q-$ value $=0$, Mascot ion score $=30$, Exp. value $=3.4 \mathrm{E}-003)$

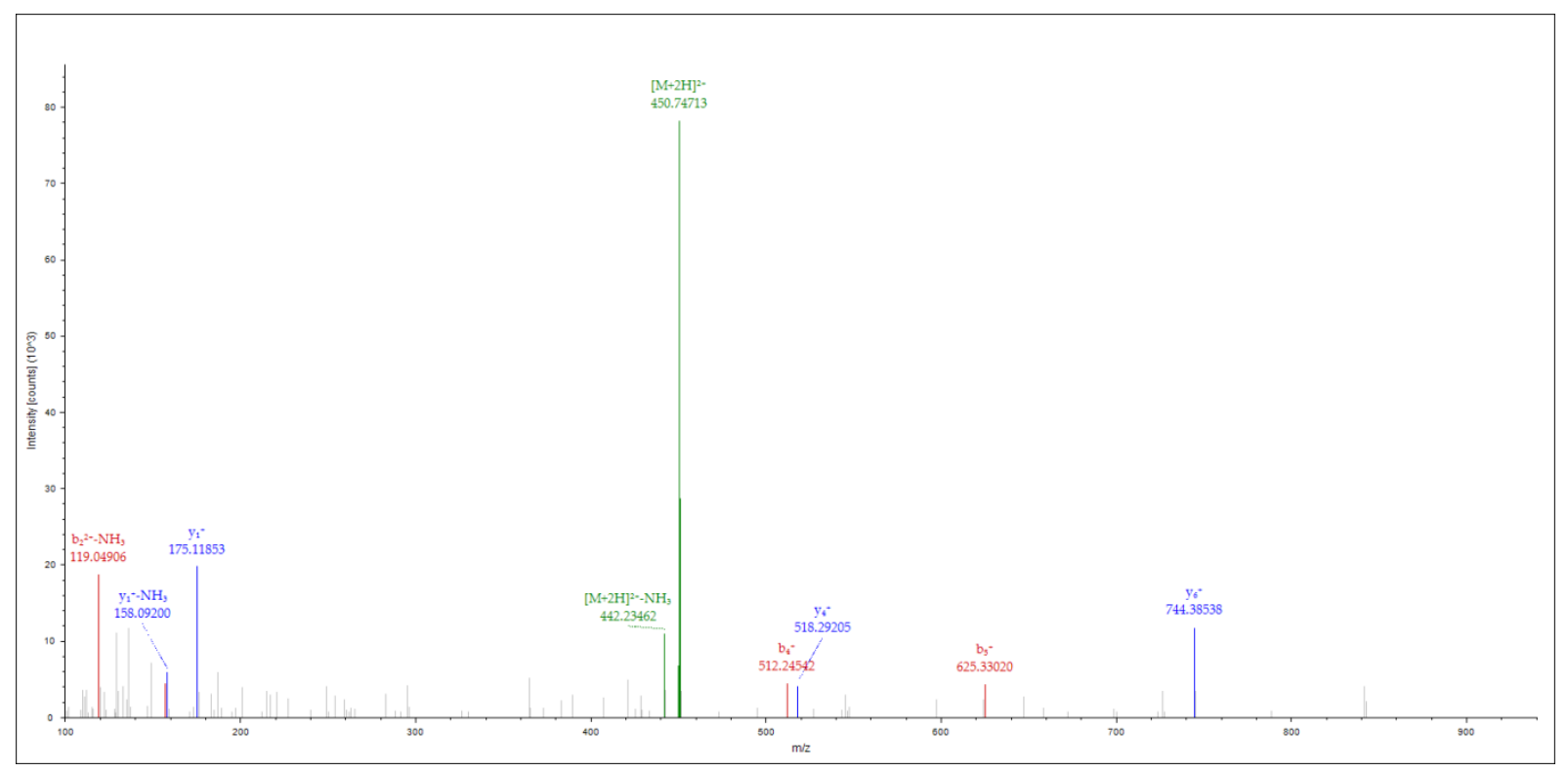

\begin{tabular}{|l|l|r|r|r|r|r|}
\hline$\# \mathbf{1}$ & $\mathbf{b}^{\mathbf{+}}$ & $\mathbf{b}^{\mathbf{2 +}}$ & $\mathbf{S e q}$ & $\mathbf{y}^{+}$ & $\mathbf{y}^{\mathbf{2 +}}$ & $\# \mathbf{2}$ \\
\hline 1 & 157.10840 & 79.05784 & $\mathrm{R}$ & & & 7 \\
\hline 2 & 254.16117 & 127.58422 & $\mathrm{P}$ & 744.38868 & 372.69798 & 6 \\
\hline 3 & 383.20377 & 192.10552 & $\mathrm{E}$ & 647.33591 & 324.17159 & 5 \\
\hline 4 & 512.24637 & 256.62682 & $\mathrm{E}$ & 518.29331 & 259.65029 & 4 \\
\hline 5 & 625.33044 & 313.16886 & $\mathrm{I}$ & 389.25071 & 195.12899 & 3 \\
\hline 6 & 726.37812 & 363.69270 & $\mathrm{~T}$ & 276.16664 & 138.58696 & 2 \\
\hline 7 & & & $\mathrm{R}$ & 175.11896 & 88.06312 & 1 \\
\hline
\end{tabular}


VVSPGFR $(q-$ value $=0.006$, Mascot ion score $=33$, Exp. value $=2.5 \mathrm{E}-003)$

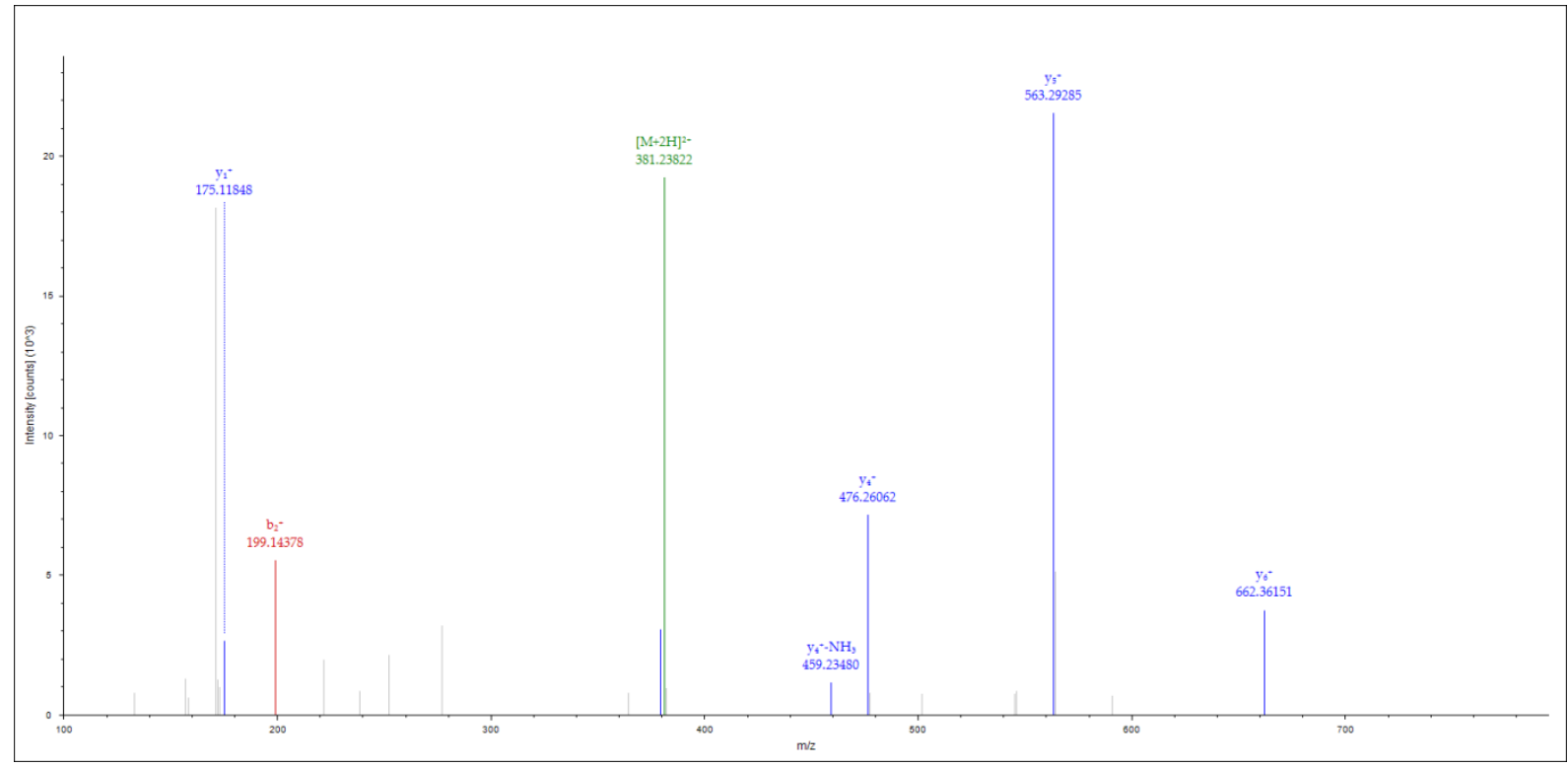

\begin{tabular}{|c|c|r|r|r|r|r|}
\hline$\# \mathbf{1}$ & $\mathbf{b}^{+}$ & $\mathbf{b}^{\mathbf{2 +}}$ & $\mathbf{S e q}$ & $\mathbf{y}^{+}$ & $\mathbf{y}^{\mathbf{2 +}}$ & $\# \mathbf{2}$ \\
\hline 1 & 100.07570 & 50.54149 & $\mathrm{~V}$ & & & 7 \\
\hline 2 & 199.14412 & 100.07570 & $\mathrm{~V}$ & 662.36207 & 331.68467 & 6 \\
\hline 3 & 286.17615 & 143.59171 & $\mathrm{~S}$ & 563.29365 & 282.15046 & 5 \\
\hline 4 & 383.22892 & 192.11810 & $\mathrm{P}$ & 476.26162 & 238.63445 & 4 \\
\hline 5 & 440.25039 & 220.62883 & $\mathrm{G}$ & 379.20885 & 190.10806 & 3 \\
\hline 7 & 587.31881 & 294.16304 & $\mathrm{~F}$ & 322.18738 & 161.59733 & 2 \\
\hline
\end{tabular}


DSTQDSFR $(q-v a l u e=0.018$, Mascot ion score $=47$, Exp. value $=3.1 \mathrm{E}-005)$

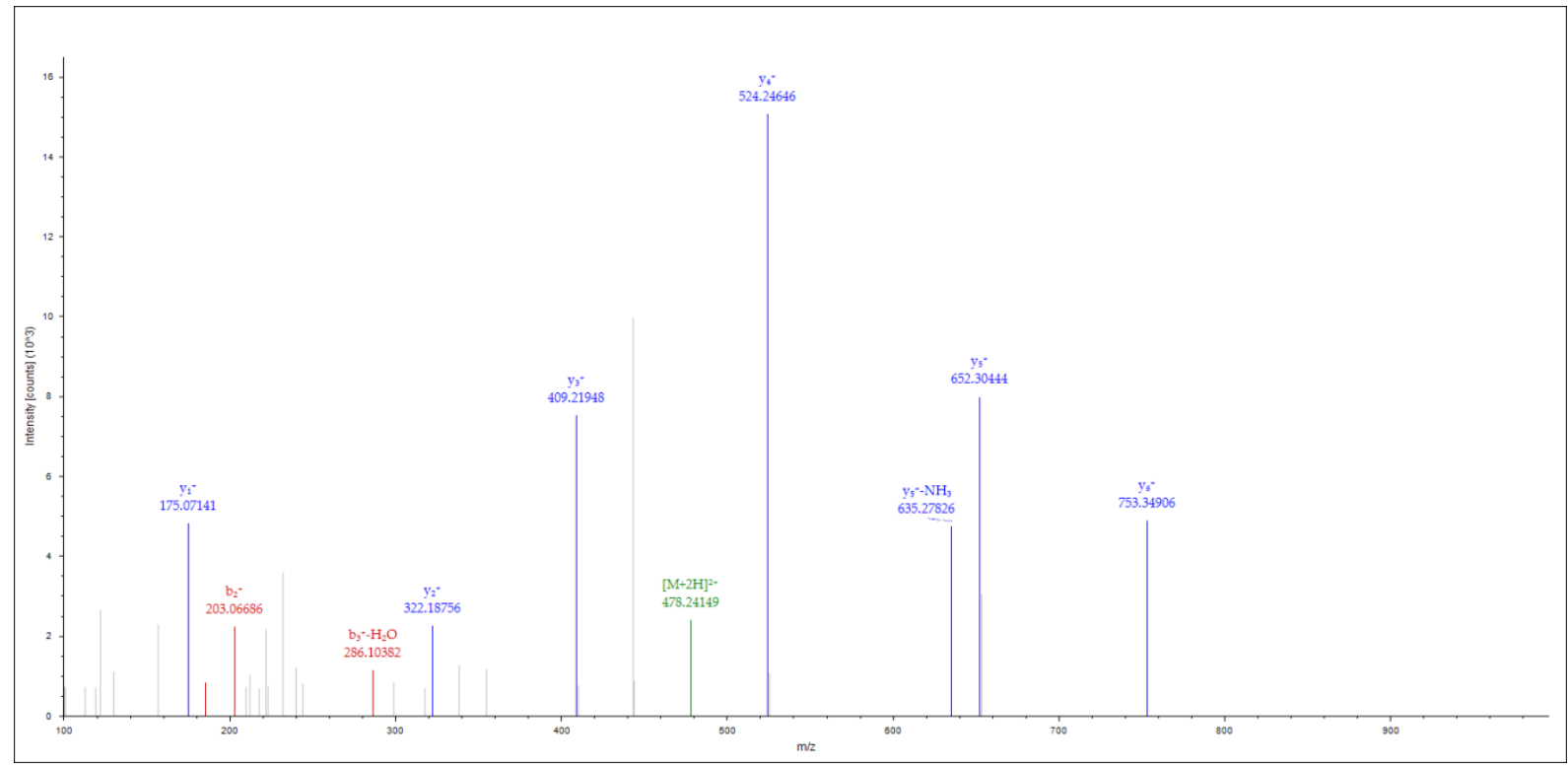

\begin{tabular}{|c|c|c|c|c|c|c|}
\hline$\# \mathbf{1}$ & $\mathbf{b}^{+}$ & $\mathbf{b}^{\mathbf{2 +}}$ & Seq. & $\mathbf{y}^{+}$ & $\mathbf{y}^{\mathbf{+ +}}$ & $\# \mathbf{2}$ \\
\hline 1 & 116.03423 & 58.52075 & $\mathrm{D}$ & & & 8 \\
\hline 2 & 203.06626 & 102.03677 & $\mathrm{~S}$ & 840.38465 & 420.69596 & 7 \\
\hline 3 & 304.11394 & 152.56061 & $\mathrm{~T}$ & 753.35262 & 377.17995 & 6 \\
\hline 4 & 432.17252 & 216.58990 & $\mathrm{Q}$ & 652.30494 & 326.65611 & 5 \\
\hline 5 & 547.19947 & 274.10337 & $\mathrm{D}$ & 524.24636 & 262.62682 & 4 \\
\hline 6 & 634.23150 & 317.61939 & $\mathrm{~S}$ & 409.21941 & 205.11334 & 3 \\
\hline 7 & 781.29992 & 391.15360 & $\mathrm{~F}$ & 322.18738 & 161.59733 & 2 \\
\hline 8 & & & $\mathrm{R}$ & 175.11896 & 88.06312 & 1 \\
\hline
\end{tabular}


GVPVSPmH (q-value $=0.018$, Mascot ion score $=42$, Exp. value $=5.1 \mathrm{E}-004)$

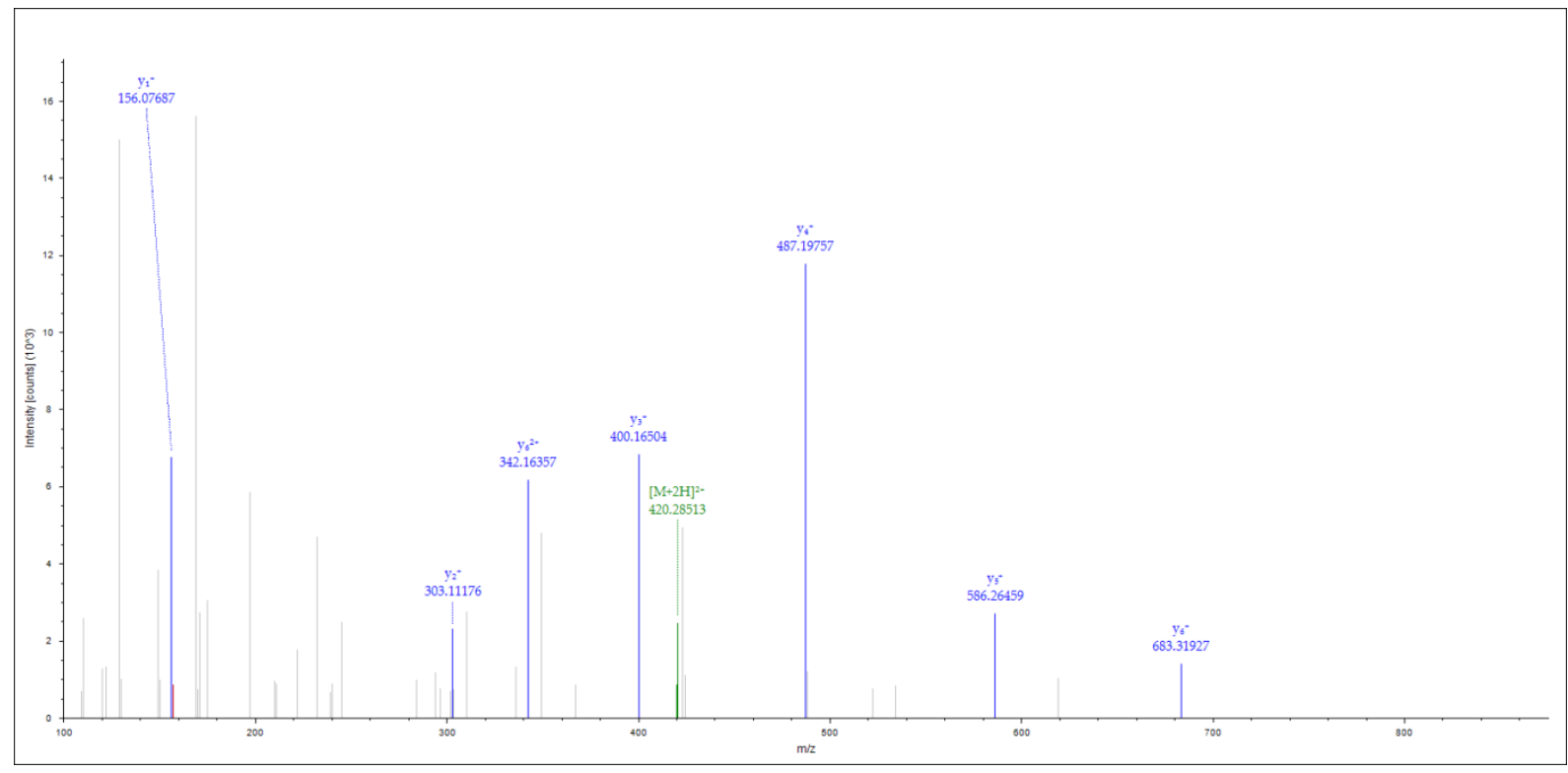

\begin{tabular}{|l|l|l|l|l|l|l|}
\hline$\# \mathbf{1}$ & $\mathbf{b}^{+}$ & $\mathbf{b}^{\mathbf{2 +}}$ & Seq. & $\mathbf{y}^{+}$ & $\mathbf{y}^{\mathbf{+}}$ & $\# \mathbf{2}$ \\
\hline $\mathbf{1}$ & 58.02875 & 29.51801 & $\mathrm{G}$ & & & 8 \\
\hline 2 & 157.09717 & 79.05222 & $\mathrm{~V}$ & 782.38658 & 391.69693 & 7 \\
\hline 3 & 254.14994 & 127.57861 & $\mathrm{P}$ & 683.31816 & 342.16272 & 6 \\
\hline 4 & 353.21836 & 177.11282 & $\mathrm{~V}$ & 586.26539 & 293.63633 & 5 \\
\hline 5 & 440.25039 & 220.62883 & $\mathrm{~S}$ & 487.19697 & 244.10212 & 4 \\
\hline 6 & 537.30316 & 269.15522 & $\mathrm{P}$ & 400.16494 & 200.58611 & 3 \\
\hline 7 & 684.33857 & 342.67292 & M-Oxidation & 303.11217 & 152.05972 & 2 \\
\hline 8 & & & H & 156.07675 & 78.54201 & 1 \\
\hline
\end{tabular}


LTPmEFGNLQK $(q-v a l u e=0.018$, Mascot ion score $=21$, Exp. value $=6.3 \mathrm{E}-002)$

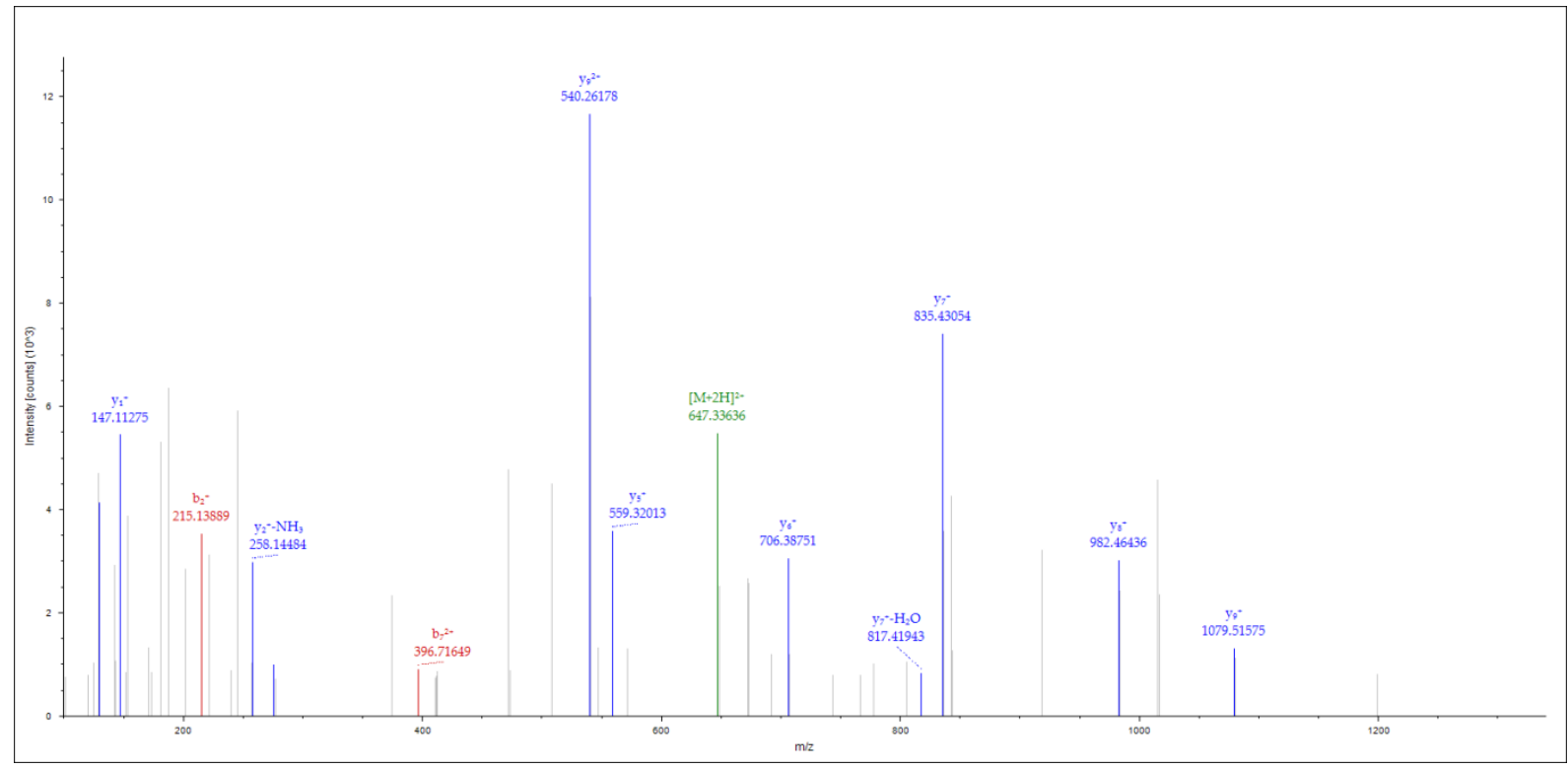

\begin{tabular}{|c|c|c|c|c|c|c|}
\hline$\# 1$ & $\mathbf{b}^{+}$ & $\mathbf{b}^{2+}$ & Seq. & $\mathbf{y}^{+}$ & $\mathbf{y}^{2+}$ & $\# 2$ \\
\hline 1 & 114.09135 & 57.54931 & L & & & 11 \\
\hline 2 & 215.13903 & 108.07315 & $\mathrm{~T}$ & 1180.56675 & 590.78701 & 10 \\
\hline 3 & 312.19180 & 156.59954 & $P$ & 1079.51907 & 540.26317 & 9 \\
\hline 4 & 459.22721 & 230.11724 & M-Oxidation & 982.46630 & 491.73679 & 8 \\
\hline 5 & 588.26981 & 294.63854 & $E$ & 835.43088 & 418.21908 & 7 \\
\hline 6 & 735.33823 & 368.17275 & $\mathrm{~F}$ & 706.38828 & 353.69778 & 6 \\
\hline 7 & 792.35970 & 396.68349 & G & 559.31986 & 280.16357 & 5 \\
\hline 8 & 906.40263 & 453.70495 & $\mathrm{~N}$ & 502.29839 & 251.65283 & 4 \\
\hline 9 & 1019.48670 & 510.24699 & L & 388.25546 & 194.63137 & 3 \\
\hline 10 & 1147.54528 & 574.27628 & $Q$ & 275.17139 & 138.08933 & 2 \\
\hline 11 & & & $\mathrm{~K}$ & 147.11281 & 74.06004 & 1 \\
\hline
\end{tabular}


TFDGDVFR $(\mathrm{q}-\mathrm{value}=0.031$, Mascot ion score $=25$, Exp. value $=2.2 \mathrm{E}-002)$

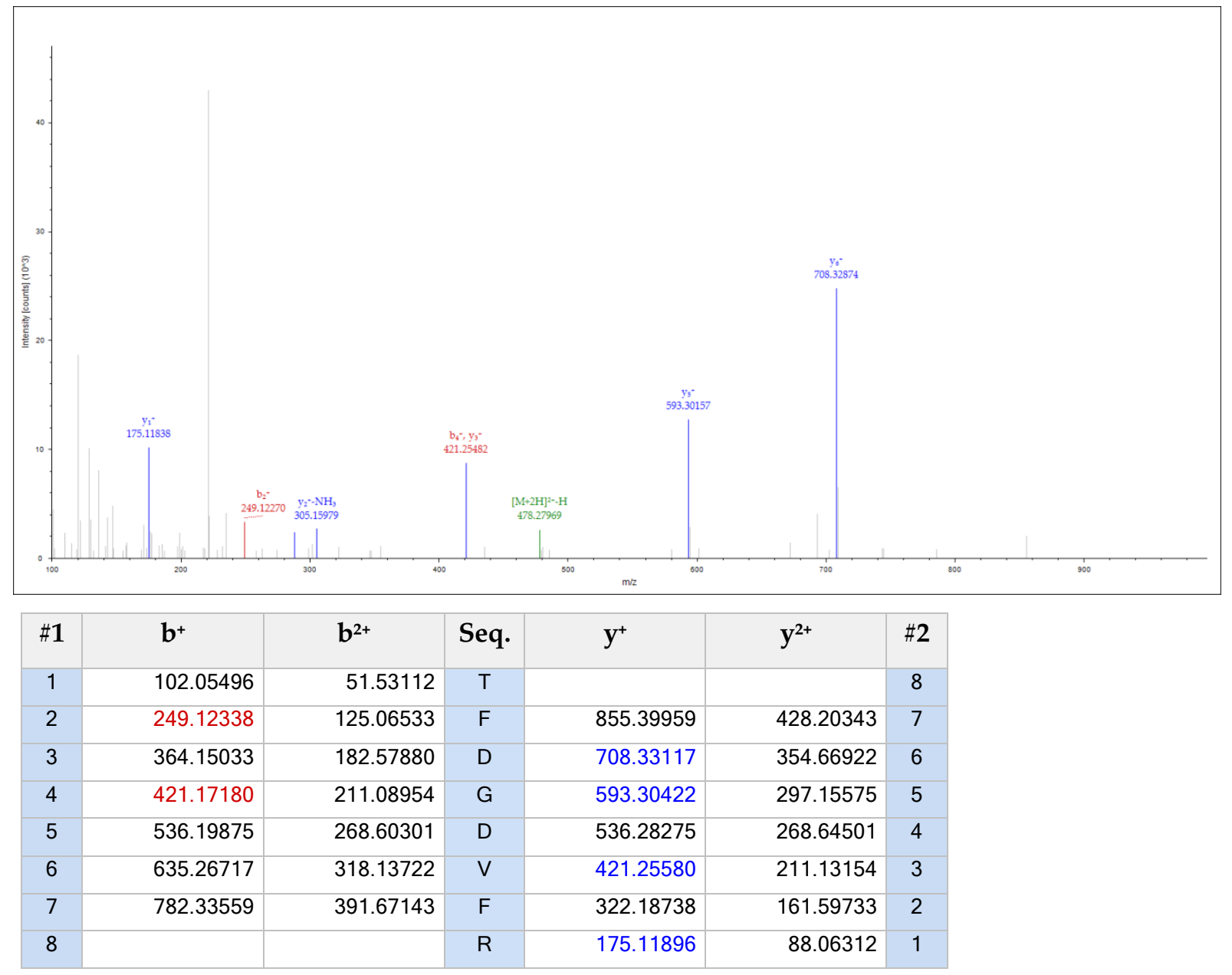



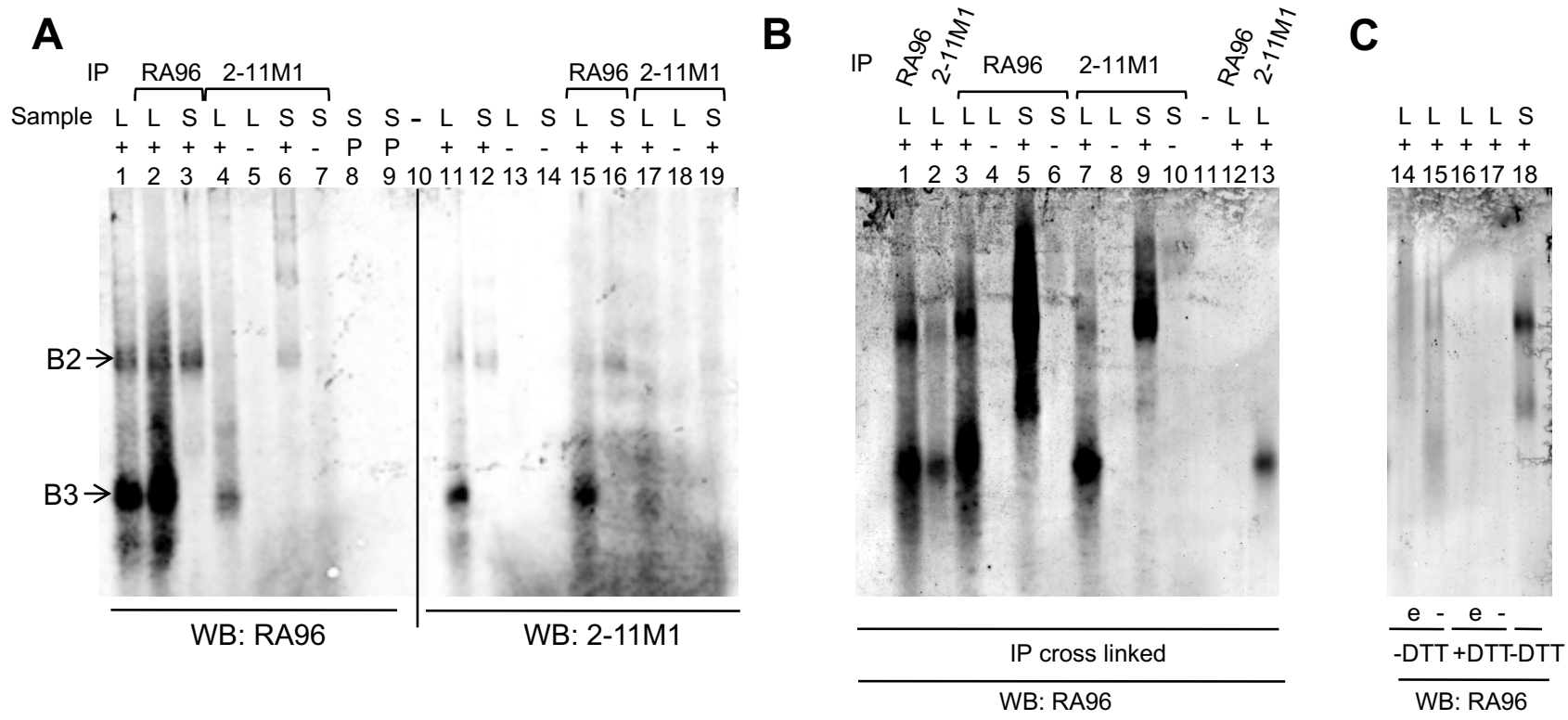

Supplementary Figure 3. Immune precipitation (IP) without cross linking (A) and with cross linked antibodies (B). Affinity beads were generated by RA96 antibodies and anti MUC5AC clone 2-11M1 antibodies without (A) or with (B) crosslinking to protein $G$ dynabeads by DMP (Pierce, according to manufacturer protocol). Lysates or secretomes of positive (A) or negative cell lines $(P)$ were used as antigen source. A. The immune complexes generated by different antibodies were separated in duplicate on the $1 \%$ agarose gel without DTT and detected by RA96 and anti MUC5AC clone 2-11 as indicated. B. The bead fraction after elution with low pH buffer (B: lane $1+2)$, the eluates (B: lane $12+13)$, and the whole IP samples (B: lane 3-10) were analyzed by RA96. A secretome sample of positive cells (A818-1) were separated as a western control. C. The addition of deglycosidase enzymes (e) did not affect the reactivity to RA96, whereas the buffer condition of deglycosylation reaction itself diminished the reactivity of RA96 signals. Abbreviations: L: Iysate; S: secretome, A, A818; P, Panctu II, e, deglycosidases (according to Calbiochem protocol); DTT: dithiothrietol; IP: immunoprecipitation. 

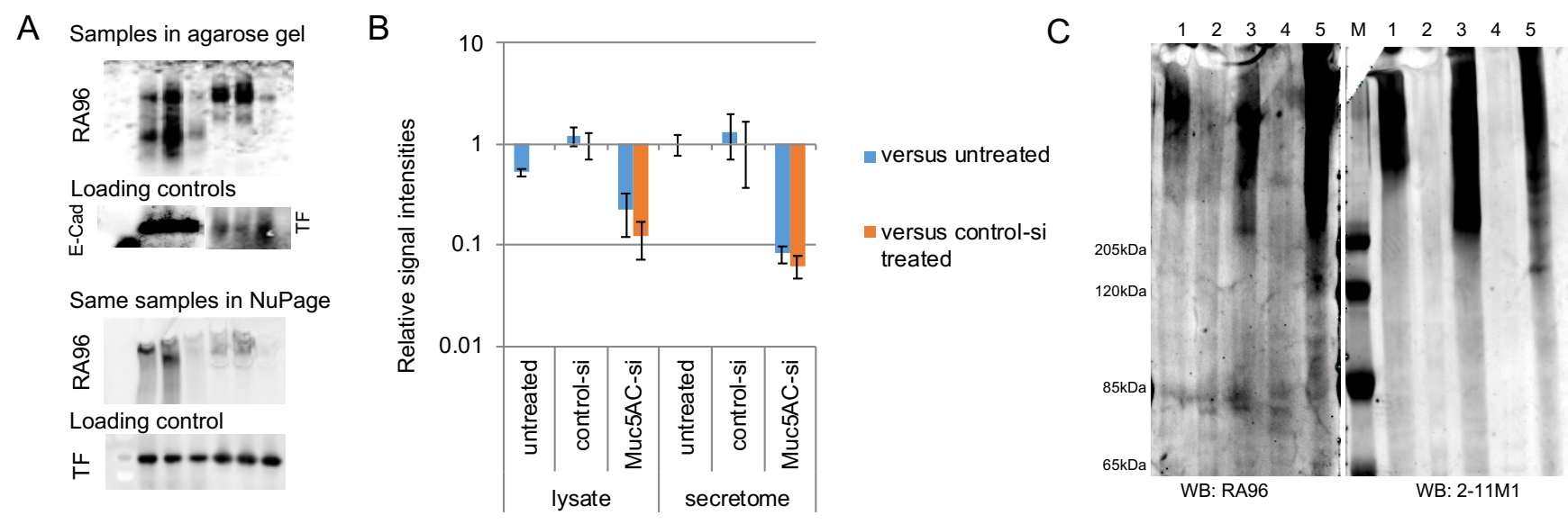

Supplementary Figure 4. MUC5AC siRNA experiments and reexpression. MUC5AC siRNA experiments and reexpression. A. Western blot analysis of on-target plus siRNA treated A818 cells. Lane 2, 5 samples of untreated cells, lane 3, 6 samples treated with control siRNA, and 4,7 samples treated with MUC5AC siRNAs. The blots were additionally probed with anti-ECadherin (E-Cad) or anti-transferrin (TF) to control the loading amount of samples. B. The diagram shows the relative signal intensities of the si-RNA treatments in the near infrared detection system (Odyssey Licor). C. Reexpression of MUC5AC fragments probed by RA96 antibodies and anti MUC5AC 2-11M1 (Biomol) in Cos7 cells. Lysate $(50 \mu \mathrm{g})$ of Cos7 cells transfected with Muc5AC constructs: lane 1. N+2TR+C, lane $2 \mathrm{C}$-term, lane $3 \mathrm{~N}$-term, lane 4 empty vector, lane 5 A818 control lysate. 


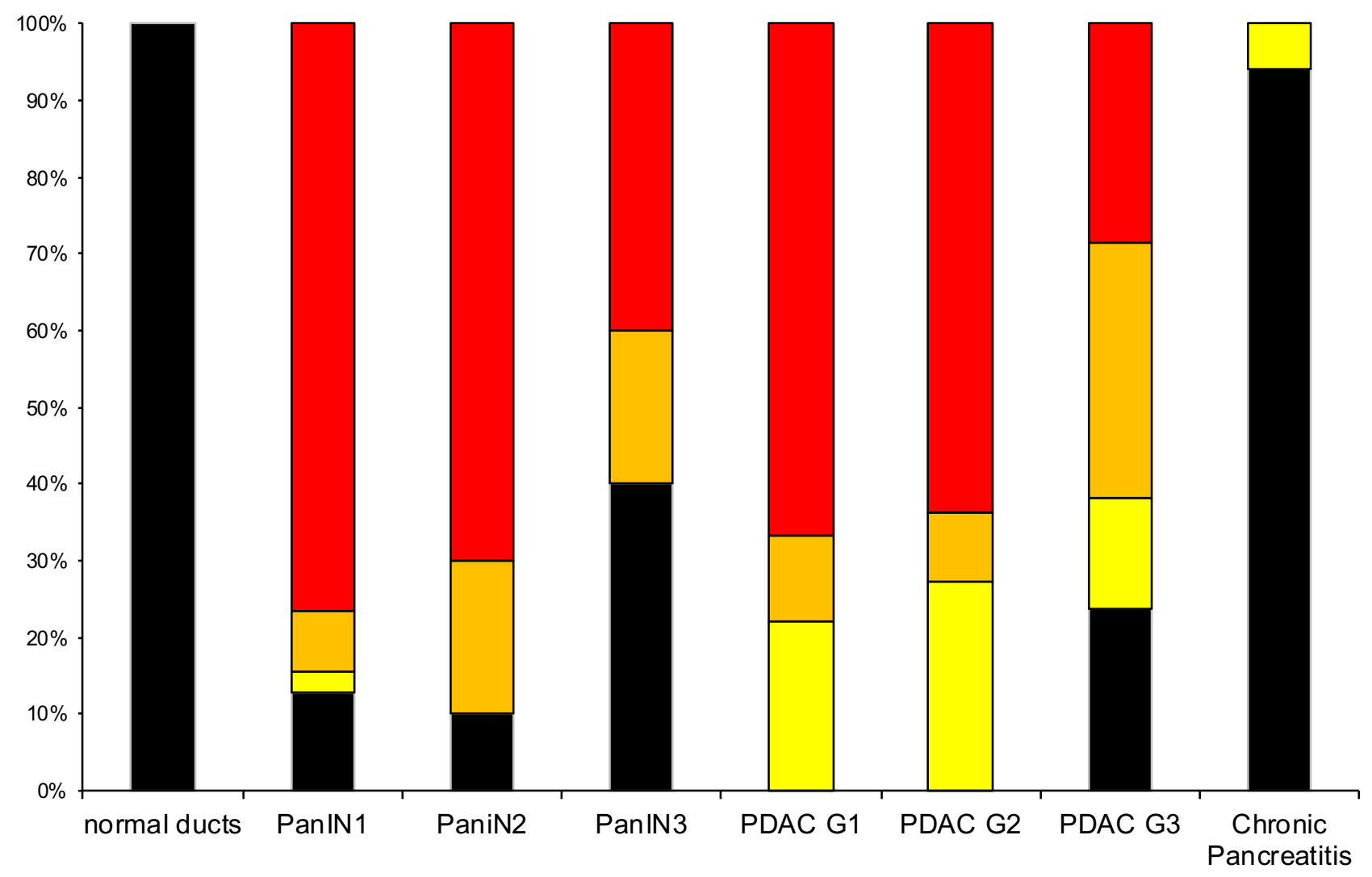

\begin{tabular}{|c|c|c|c|c|}
\hline & no & weak & moderate & strong \\
\hline normal ducts & 34 & 0 & 0 & 0 \\
\hline PanIN1 & 10 & 2 & 6 & 59 \\
\hline PaniN2 & 2 & 0 & 4 & 14 \\
\hline PanIN3 & 2 & 0 & 1 & 2 \\
\hline PDAC G1 & 0 & 4 & 2 & 12 \\
\hline PDAC G2 & 0 & 6 & 2 & 14 \\
\hline PDAC G3 & 5 & 3 & 7 & 6 \\
\hline Chronic Pancreatitis & 32 & 2 & & \\
\hline
\end{tabular}

Supplemental Figure 5. Quantification of IHC with RA96 antibody in clinical samples. There is $100 \%$ no staining in normal ducts, over $>90 \%$ no staining in chronic pancreatitis (CP). There is a gradual increase of MUC5AC expression with grade (G1-G3) and level (PanIN vs. PDAC) of pancreatic cancer. 

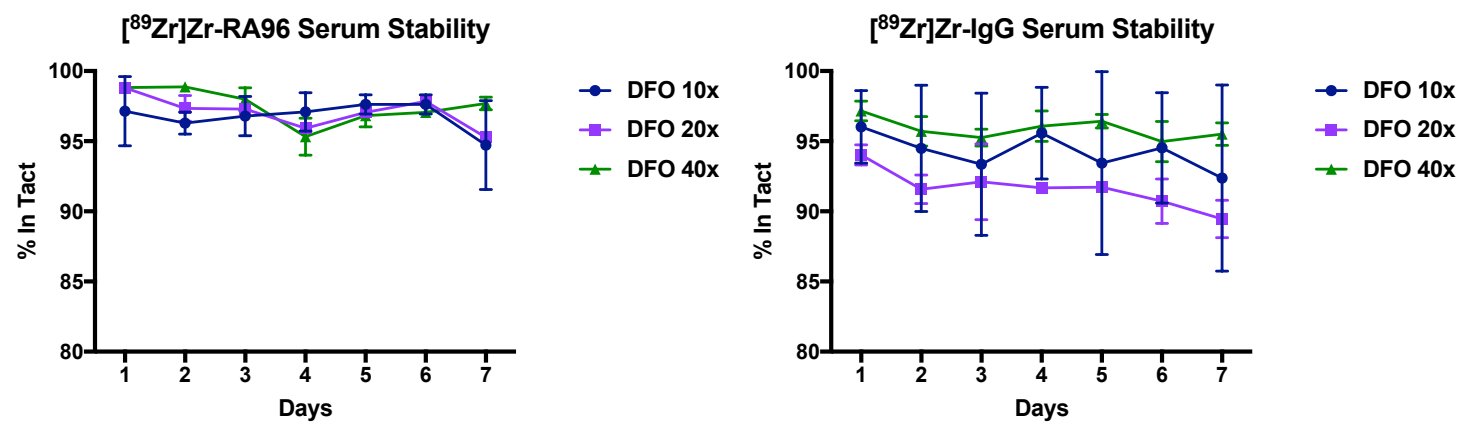

Supplementary Figure 6 . Serum stability of radiolabeled RA96 and IgG for out to 1 week.

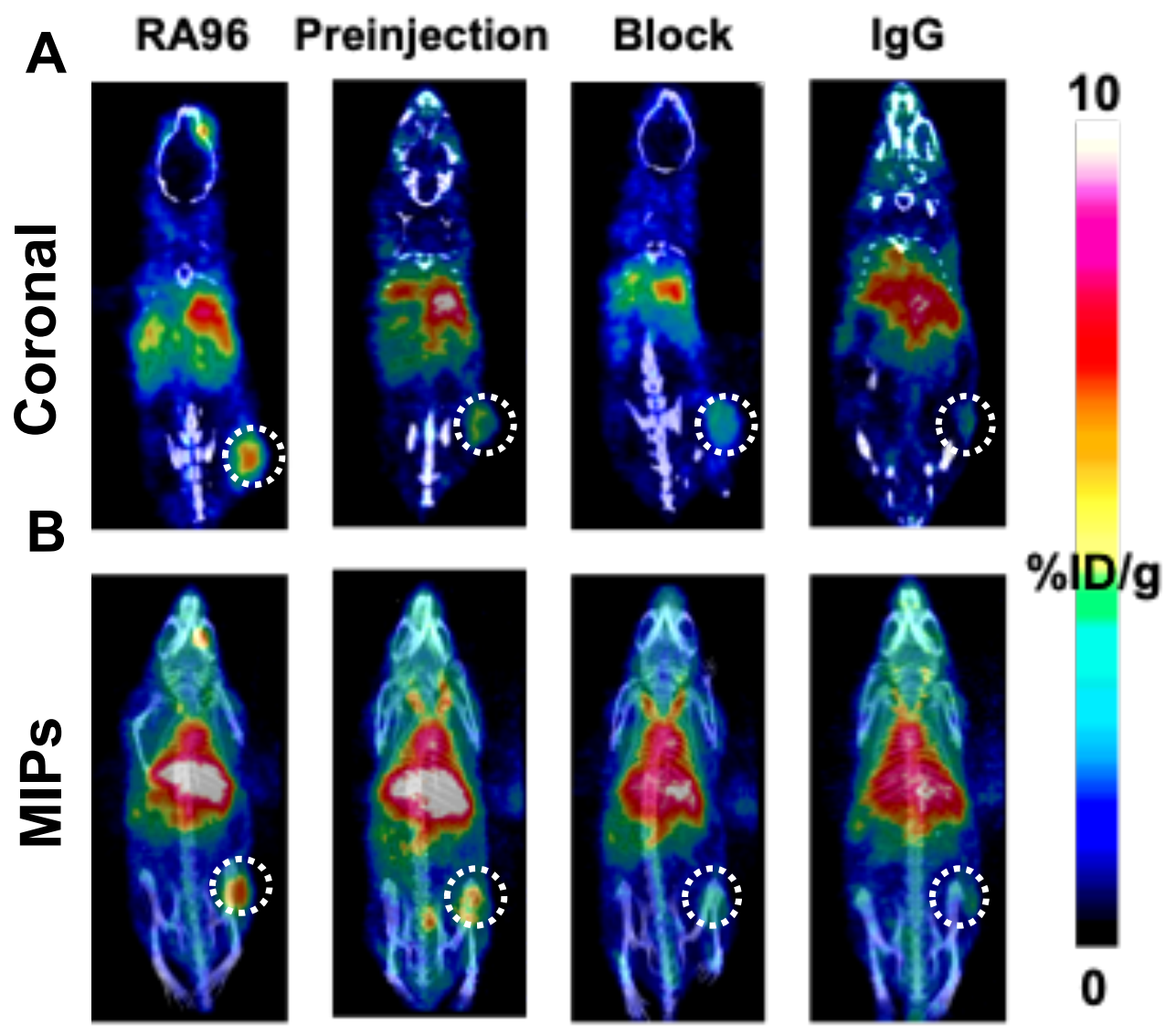

Supplementary Figure 7. Serial PET/CT imaging of [ $\left.{ }^{89} \mathrm{Zr}\right] \mathrm{Zr}$-DFO-RA96 and [ $\left.{ }^{89} \mathrm{Zr}\right] \mathrm{Zr}$-DFOIgG with corresponding ex vivo biodistribution at $\mathbf{2 4} \mathbf{~ h}$. Images are represented as coronal slices (A) and maximum intensity projections (B). Tumors are on the right flank and indicated by the dotted line. Significant differences are noted when comparing the $\left.{ }^{89} \mathrm{Zr}\right] \mathrm{Zr}$-DFO-RA96 to all control groups $(P<0.001)$. Pre-injection: indicates a partial block, with $3 \times$ amount of unlabeled 
antibody injected $4 \mathrm{~h}$ prior to injection with [ $\left.{ }^{89} \mathrm{Zr}\right] \mathrm{Zr}$-DFO-RA96. Block: full block with $30 \times$ amount of unlabeled antibody coinjected with [ ${ }^{89} \mathrm{Zr}$ ]Zr-DFO-RA96. IgG: injection of isotype-matched control [ $\left.{ }^{89} \mathrm{Zr}\right] \mathrm{Zr}-\mathrm{DFO}-\mathrm{IgG}$.

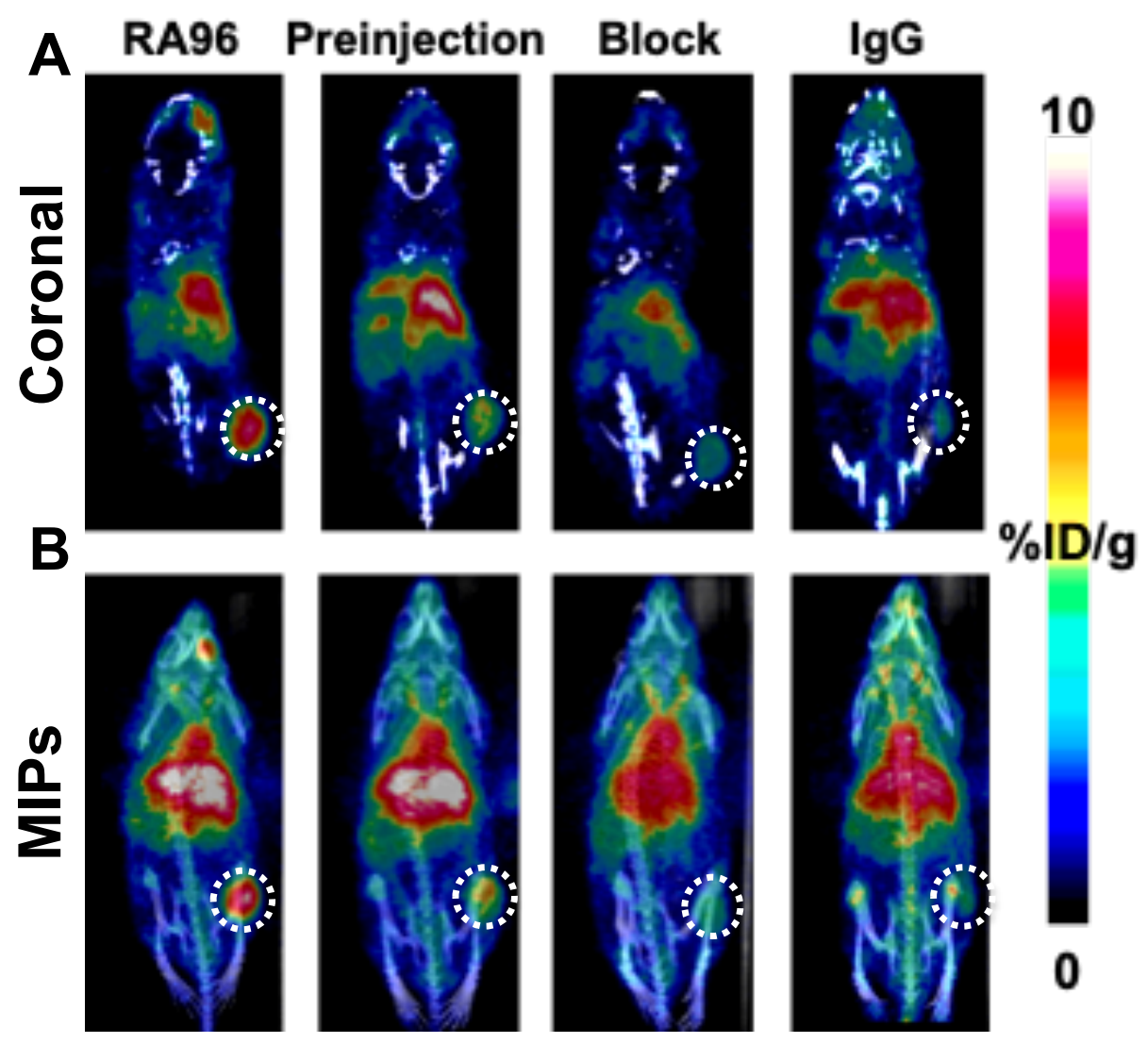

Supplementary Figure 8 . Serial PET/CT imaging of [ $\left.{ }^{89} \mathrm{Zr}\right] \mathrm{Zr}-\mathrm{DFO}-\mathrm{RA} 96$ and $\left[{ }^{89} \mathrm{Zr}\right] \mathrm{Zr}$-DFOIgG with corresponding ex vivo biodistribution at $\mathbf{7 2} \mathbf{~ h}$. Images are represented as coronal slices $(A)$ and maximum intensity projections (B). Tumors are on the right flank and indicated by the dotted line. Significant differences are noted when comparing the $\left.{ }^{89} \mathrm{Zr}\right] \mathrm{Zr}$-DFO-RA96 to all control groups $(P<0.001)$. Pre-injection: indicates a partial block, with $3 \times$ amount of unlabeled antibody injected $4 \mathrm{~h}$ prior to injection with [ $\left.{ }^{89} \mathrm{Zr}\right] \mathrm{Zr}$-DFO-RA96. Block: full block with 30x amount of unlabeled antibody coinjected with [ ${ }^{89} \mathrm{Zr}$ ]Zr-DFO-RA96. IgG: injection of isotype-matched control $\left[{ }^{89} \mathrm{Zr}\right] Z r-D F O-I g G$. 


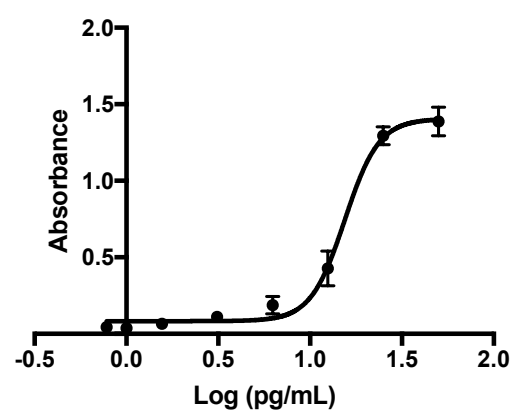

\begin{tabular}{|c|c|c|c|c|c|c|c|c|c|c|c|c|}
\hline & & & \multicolumn{5}{|c|}{$\lg G$} & \multicolumn{5}{|c|}{ RA96 } \\
\hline & 1 & 2 & 3 & 4 & 5 & 6 & 7 & 8 & 9 & 10 & 11 & 12 \\
\hline 1 & STDs & STDs & $2 x$ diluted & $2 x$ diluted & $2 x$ diluted & $2 x$ diluted & $B$ & $2 x$ diluted & $2 x$ diluted & $2 x$ diluted & $2 x$ diluted & $2 x$ diluted \\
\hline 2 & STDs & STDs & $4 \mathrm{x}$ diluted & $4 x$ diluted & $4 x$ diluted & $4 x$ diluted & $B$ & $4 x$ diluted & $4 x$ diluted & $4 x$ diluted & $4 x$ diluted & $4 x$ diluted \\
\hline 3 & STDs & STDs & $8 \mathrm{x}$ diluted & $8 x$ diluted & $8 x$ diluted & $8 x$ diluted & $B$ & $8 x$ diluted & $8 x$ diluted & $8 x$ diluted & $8 x$ diluted & $8 x$ diluted \\
\hline 4 & STDs & STDs & $16 \times$ diluted & $16 \times$ diluted & $16 \times$ diluted & $16 \times$ diluted & $B$ & $16 \mathrm{x}$ diluted & $16 \times$ diluted & $16 \times$ diluted & $16 \times$ diluted & $16 \times$ diluted \\
\hline 5 & STDs & STDs & $2 x$ diluted & $2 x$ diluted & $2 x$ diluted & $2 x$ diluted & $2 x$ diluted & $2 x$ diluted & $2 x$ diluted & $2 x$ diluted & $2 x$ diluted & $2 x$ diluted \\
\hline 6 & STDs & STDs & $4 x$ diluted & $4 x$ diluted & $4 \mathrm{x}$ diluted & $4 x$ diluted & $4 x$ diluted & $4 x$ diluted & $4 x$ diluted & $4 x$ diluted & $4 x$ diluted & $4 x$ diluted \\
\hline 7 & STDs & STDs & $8 x$ diluted & $8 x$ diluted & $8 x$ diluted & $8 x$ diluted & $8 x$ diluted & $8 x$ diluted & $8 x$ diluted & $8 x$ diluted & $8 x$ diluted & $8 x$ diluted \\
\hline 8 & STDs & STDs & $16 x$ diluted & $16 x$ diluted & $16 x$ diluted & 16x diluted & 16x diluted & $16 x$ diluted & $16 x$ diluted & 16x diluted & 16x diluted & $16 x$ diluted \\
\hline & & & \multicolumn{5}{|c|}{ RA96 + Preinjection } & \multicolumn{5}{|c|}{ RA96 + Block } \\
\hline
\end{tabular}

\begin{tabular}{|c|c|c|c|c|c|c|c|c|c|c|c|c|}
\hline & \multicolumn{2}{|c|}{ STDs } & \multicolumn{5}{|c|}{$\lg G$} & \multicolumn{5}{|c|}{ RA96 } \\
\hline & 1 & 2 & 3 & 4 & 5 & 6 & 7 & 8 & 9 & 10 & 11 & 12 \\
\hline 1 & 1.32 & 1.45 & 0.0252 & 0.0255 & 0.0288 & 0.0238 & 0.0304 & 0.034 & 0.0478 & 0.029 & 0.0317 & 0.0251 \\
\hline 2 & 1.25 & 1.34 & 0.0296 & 0.0284 & 0.023 & 0.023 & 0.0429 & 0.0363 & 0.0396 & 0.0371 & 0.0264 & 0.0447 \\
\hline 3 & 0.35 & 0.51 & 0.0426 & 0.0305 & 0.0214 & 0.0254 & 0.0386 & 0.0461 & 0.0472 & 0.0321 & 0.039 & 0.0374 \\
\hline 4 & 0.23 & 0.15 & 0.0277 & 0.0308 & 0.0239 & 0.0372 & 0.0436 & 0.055 & 0.0543 & 0.0333 & 0.0173 & 0.034 \\
\hline 5 & 0.11 & 0.12 & 0.0283 & 0.0245 & 0.0111 & 0.0213 & 0.0197 & 0.0211 & 0.0319 & 0.0263 & 0.0264 & 0.0309 \\
\hline 6 & 0.06 & 0.07 & 0.0267 & 0.0256 & 0.0267 & 0.0288 & 0.0337 & 0.0215 & 0.0304 & 0.0285 & 0.0296 & 0.0275 \\
\hline 7 & 0.04 & 0.04 & 0.0269 & 0.0259 & 0.0278 & 0.0242 & 0.048 & 0.0203 & 0.0288 & 0.0268 & 0.0321 & 0.0332 \\
\hline \multirow[t]{2}{*}{8} & 0.03 & 0.04 & 0.039 & 0.0475 & 0.0137 & 0.0451 & 0.0412 & 0.0373 & 0.0336 & 0.0396 & 0.0388 & 0.0235 \\
\hline & & & \multicolumn{5}{|c|}{ RA96 + Preinjection } & \multicolumn{5}{|c|}{ RA96 + Block } \\
\hline
\end{tabular}

Supplementary Figure 9. ELISA standard curve, experimental set up, and raw data. 


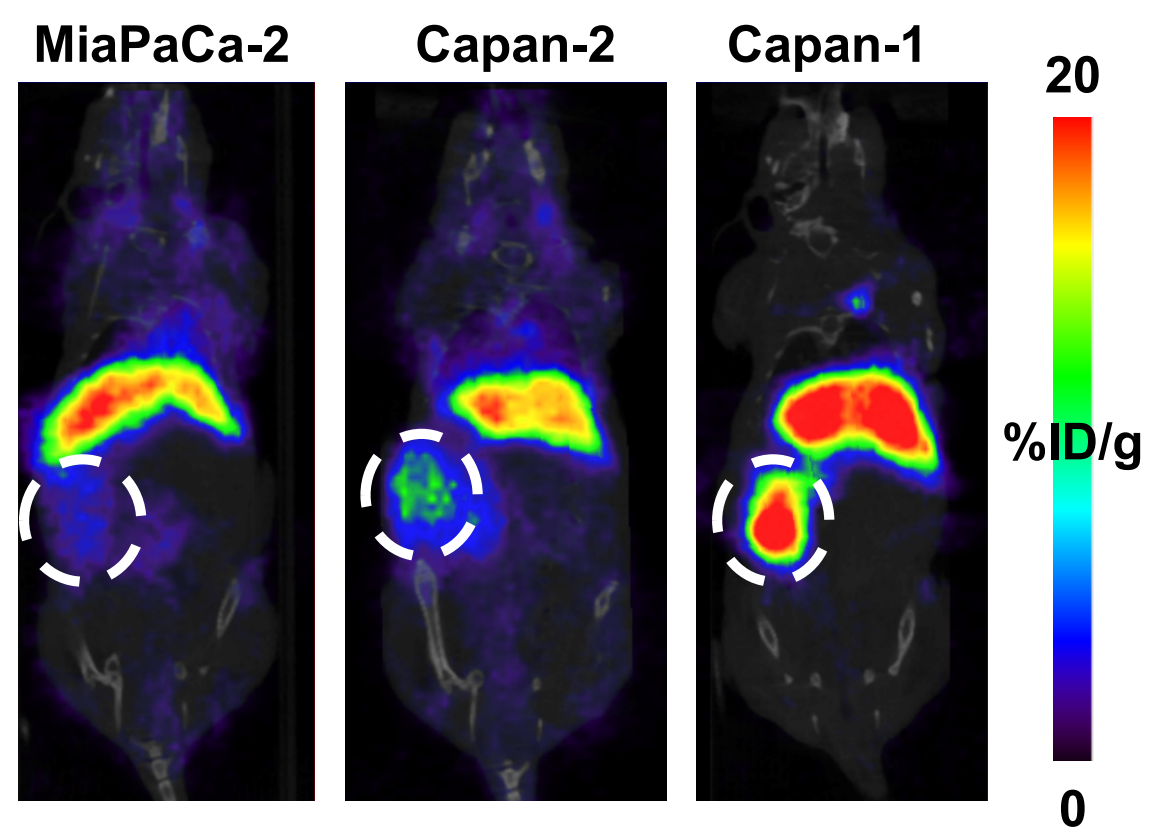

Supplementary Figure 10. PET/CT imaging of [ $\left.{ }^{89} \mathrm{Zr}\right] \mathrm{Zr}-\mathrm{DFO}-\mathrm{RA} 96$ at $72 \mathrm{~h}$ post-injection. Images are represented as coronal slices in MIA PaCa-2, Capan-2, and Capan-1 tumors orthotopically implanted. 